\title{
A dynamic North-South model of demand-induced product cycles
}

Reto Foellmi, Sandra Hanslin and Andreas Kohler

SNB Working Papers
4/2015 


\section{Legal Issues}

\section{DISCLAIMER}

The views expressed in this paper are those of the author(s) and do not necessarily represent those of the Swiss National Bank. Working Papers describe research in progress. Their aim is to elicit comments and to further debate.

\section{COPYRIGHT@}

The Swiss National Bank (SNB) respects all third-party rights, in particular rights relating to works protected by copyright (information or data, wordings and depictions, to the extent that these are of an individual character).

SNB publications containing a reference to a copyright (C) Swiss National Bank/SNB, Zurich/year, or similar) may, under copyright law, only be used (reproduced, used via the internet, etc.) for non-commercial purposes and provided that the source is mentioned. Their use for commercial purposes is only permitted with the prior express consent of the SNB.

General information and data published without reference to a copyright may be used without mentioning the source. To the extent that the information and data clearly derive from outside sources, the users of such information and data are obliged to respect any existing copyrights and to obtain the right of use from the relevant outside source themselves.

\section{LIMITATION OF LIABILITY}

The SNB accepts no responsibility for any information it provides. Under no circumstances will it accept any liability for losses or damage which may result from the use of such information. This limitation of liability applies, in particular, to the topicality, accuracy, validity and availability of the information.

ISSN 1660-7716 (printed version)

ISSN 1660-7724 (online version)

(C) 2015 by Swiss National Bank, Börsenstrasse 15,

P.O. Box, $\mathrm{CH}-8022$ Zurich 


\title{
A DYNAMic NorTh-SOUth MOdel OF DEMAND-INDUCED PRODUCT CYCLES*
}

\author{
Reto Foellmi ${ }^{\dagger} \quad$ Sandra Hanslin ${ }^{\ddagger} \quad$ Andreas Kohler $\S$
}

February 2015

\begin{abstract}
This paper presents a dynamic North-South general-equilibrium model where households have non-homothetic preferences. Innovation takes place in a rich North while firms in a poor South imitate products manufactured in the North. Introducing non-homothetic preferences delivers a complete international product cycle as described by Vernon (1966), where the different stages of the product cycle are determined not only by supply side factors but also by the distribution of income between North and South. We ask how changes in Southern labour productivity, population size in the South and inequality across regions affect the international product cycle. In line with presented stylised facts about the product cycle we predict a negative correlation between adoption time and per capita incomes.
\end{abstract}

JEL classification: F1, O3

Keywords: Product cycles, Inequality, International trade

\footnotetext{
${ }^{*}$ We thank Josef Zweimüller, Peter Neary, Jim Markusen, Fabrizio Zilibotti, Kiminori Matsuyama, Claudia Bernasconi and Andreas Steinhauer for valuable discussions. Financial support by the Swiss National Science Foundation (SNF) is gratefully acknowledged.

${ }^{\dagger}$ University of St. Gallen, Department of Economics, Bodanstrasse 8, CH-9000 St. Gallen, Switzerland, e-mail: reto.foellmi@unisg.ch

${ }^{\ddagger}$ Swiss National Bank, Zurich, Switzerland, e-mail: sandra.hanslin@snb.ch

${ }^{\S}$ Federal Department of Economic Affairs, Education and Research EAER, Agroscope, Taenikon 1, CH-8356 Ettenhausen, e-mail: andreas.kohler@agroscope.admin.ch
} 


\section{Introduction}

The recent years have seen an unprecedented expansion of international trade. This expansion went together with the entry of important emerging economies like China into the world market. This raises the question what are the global implications for innovations and long-run productivity growth? At first sight, there are two opposing forces at play. On the one hand, the rise of emerging economies triggers quicker imitation of Northern innovations; but on the other hand, when per capita incomes play a role for demand, the growing incomes of consumers raise market demand for innovative products.

To analyze this question we take up the idea of the international product cycle, first proposed by Vernon (1966). He hypothesized that new goods would be introduced in countries with high per capita incomes (catering to the needs of such a market), after some time demand for these goods emerges in poorer countries abroad as incomes grow and exports start. Later on, goods are imitated by less advanced countries, which have a relative cost advantage, such that the production moves there. Completing the cycle, goods that were once exported by rich countries are eventually imported by them. In a follow-up paper, Vernon (1979) explicitly emphasized the role of the demand side in shaping the typical product cycle:

In the early part of the post-war period, the US economy was the repository of a storehouse of innovations not yet exploited abroad, innovations that responded to the labour-scarce high-income conditions of the US market. As the years went on, other countries eventually achieved the income levels and acquired the relative labour costs that had prevailed earlier in the United States. As these countries tracked the terrain already traversed by the US economy, they developed an increasing demand for the products that had previously been generated in response to US needs. That circumstance provided the consequences characteristically associated with the product cycle sequence ...(Vernon 1979, p. 260).

To model the idea that per capita income plays a role for demand, we modify Grossman and Helpman's (1991) formalization of the product cycle by replacing constant-elasticity-of-substitution (CES) preferences with non-homothetic preferences. This setup provides a demand-based dynamic model which is able to generate the three stages of the product cycle as Vernon (1966) described: (1) a product is exclusively produced and consumed in North, (2) a product is produced in North and exported to South and (3) a product is imitated and exported from South to North.

What is the contribution of non-homothetic preferences to the theory of international product cycles? Homothetic, separable CES preferences cannot deliver a complete product cycle, as each consumer always buys all goods, irrespective of her income. Hence, supply-based approaches cannot capture the fact that countries with lower per capita incomes consume products later in the cycle (i.e. the first stage mentioned above is missing). This is inconsistent with the stylized fact that product adoption strongly correlates with the level of per capita income (see Section 4). 
We analyze our question of interest in a dynamic general-equilibrium model of two regions, a wealthy North and a poor South. Households have non-homothetic preferences over differentiated products such that consumption patterns differ across regions. In particular, households in North can afford to consume more and newer products than households in South. Monopolistic firms in North innovate new products (horizontal innovations) whereas competitive firms in South randomly target Northern products for imitation. Trading products across regions is costless. ${ }^{1}$ In the steady state, products follow the following cycle: A new product is developed and introduced in North. Only after a certain time have households in South become rich enough to afford a "new" product that is produced in North. This demand lag increases in the degree of inequality across regions and decreases, ceteris paribus, with the innovation rate. ${ }^{2}$ In other words, if Southern households are relatively poor the demand lag is large. Similarly, if incomes grow at a low rate the demand lag is large too. As time elapses further, South eventually masters the technology to manufacture the product itself. Southern firms choose at random (because preferences are symmetric across products) which Northern products to imitate that have not yet been copied. ${ }^{3}$ They must invest resources in order to reverse engineer the production process of the randomly chosen product. Once they have invested the necessary resources, they enter into price competition with the innovating firm in North. Because they have a cost advantage due to lower wages, they can underbid the Northern innovator and capture the whole market. Hence, the South becomes an exporter of that product. In this model the average time span a product is being manufactured in North is determined endogenously. This mechanism describes, in the aggregate, a product cycle as described by Vernon (1966).

Attempts to formalize Vernon's product cycle date back to Krugman (1979). In his model, a advanced North introduces new products at a constant exogenous rate and a less advanced South copies those goods, also at a constant exogenous rate. Higher per capita income in North depends on quasi rents from the Northern monopoly in new goods, i.e. North must continually innovate to maintain its relative and absolute position. Subsequently, Grossman and Helpman (1991) endogenized innovation and imitation rates. In their model, long-run growth is faster the larger the resource base of the South and the more productive its resources in learning the production process. The reason is that profits during the monopoly phase are higher when a smaller number of Northern firms compete for resources in the manufacturing sector, which outweighs the effect of a higher risk-adjusted interest rate since profits accrue on average for a shorter period of time. Both models, as well as the recent work by Acemoglu, Gancia and Zilibotti (2012), focus on supply-side aspects of the product cycle theory, i.e. how the diffusion

\footnotetext{
${ }^{1}$ Obviously, this is a simplifying assumption. Its implications are discussed in Section 2.4.

${ }^{2}$ Our use of the term "demand lag" differs from Posner (1961). He thinks of the demand lag as the delay in the acceptance of foreign goods in the domestic market, i.e. foreign goods might not be considered perfect substitutes for home-produced goods until some time elapses. We define the demand lag as the time it takes in the poor South for incomes to grow sufficiently such that households there can afford to buy goods produced in North, abstracting from differences in tastes.

${ }^{3}$ The assumption of random imitation allows for the possiblity that some products skip the export stage. However, the model implies that a product follows, on average, the typical product cycle. We discuss this in Section 2.5.
} 
of technology and the determination of relative wages depend on technology parameters. In all these approaches, demand patterns in North and South are identical because agents have homothetic preferences.

There is only a small literature dealing with demand-side explanations of the product cycle. Flam and Helpman (1987) and Stokey (1991) focus on vertical innovations with quality differences between North and South. Different from our approach, Flam and Helpman (1987) rely on exogenous technical progress, whereas Stokey (1991) presents a static Ricardian trade model of different demand structures (similar examples include Matsuyama 2000, and Falkinger 1990). Our paper, in contrast, studies endogenous imitation with horizontal innovations in a dynamic general-equilibrium "new" trade model. More closely related is Kugler and Zweimüller (2005) who propose a dynamic North-South model with non-homothetic preferences. However, their model is partial-equilibrium in nature since interest rates are exogenously determined. Furthermore, the focus of their analysis is on the cross-sectional composition of aggregate demand rather than on product cycles.

The remainder of the paper is structured as follows. In Section 2, we introduce the model and solve for the steady state, and transitional dynamics. Comparative statics results of changes in Southern productivity, relative country sizes and changes in inequality across regions are discussed in Section 3. To illustrate the different stages of the product cycle we look at the case study of the countertop microwave oven (and 5 other typical consumer durables) in Section 4. Section 5 extends the model towards hierarchic preferences, and learning-by-doing. Eventually, Section 6 concludes.

\section{Model}

\subsection{Distribution and endowments}

The economy consists of two regions $i \in\{N, S\}$, an industrialized North $(N)$ and a less developed South $(S)$. The population size of the economy is $L$; a fraction $\beta$ lives in South and a fraction $(1-\beta)$ in North. We assume that each household regardless of its residence inelastically supplies one unit of labor on the local labor market. This implies that aggregate labor supply in South is given by $\beta L$, and by $(1-\beta) L$ in North. Furthermore, suppose that each household holds domestic and foreign assets. Hence, income inequality is endogenously determined and originates from differences in labor and capital incomes across countries.

With non-homothetic preferences, the difference between gross domestic and gross national product, or generally, current account imbalances play a non-trivial role. As we want to discuss a reduction of the income gap between North and South (see Section 3.3), we allow for a non-zero trade balance. To this end, we allow for a transfer system, e.g. foreign aid, between North and South. The transfer system assumes that each household in the North pays a lump-sum transfer $T_{N}(t) \geq 0$ and each household in South receives $T_{S}(t)$. The transfer system must run a balanced budget in each period such that $(1-\beta) L T_{N}(t)=\beta L T_{S}(t)$, and transfers grow at the same rate as incomes. We will take $T_{S}(t)$ as the exogenous variable so that through 
the balanced budget condition $T_{N}(t)$ is endogenously determined.

\section{$2.2 \quad$ Preferences}

There is a continuum of differentiated products in the economy indexed by $j \in[0, \infty)$, where only a subset $N(t)$ is available on the market at each point in time. We assume differentiated products to be indivisible, and model consumption as a binary decision. Hence, households consume either 1 unit of product $j$ at time $t$, or they don't consume that product at all. Note that for the sake of readability, we drop the region index $i$ where no confusion arises. Instantaneous utility is non-homothetic and takes the following form

$$
u\left(\{c(j, t)\}_{j=0}^{N(t)}\right)=\int_{0}^{N(t)} c(j, t) d j
$$

where $c(j, t)$ is an indicator function that takes the value one if product $j$ is consumed at time $t$, and zero otherwise. The indicator function $c(j, t)$ will be specific to the income group, i.e. the region. The specification of the instantaneous utility function contrasts with the constant-elasticity-of-substitution (CES) form as follows. With zero-one preferences households can only choose consumption along the extensive margin, i.e. choose how many different products they want to purchase, whereas with CES preferences they can only choose consumption along the intensive margin, i.e. how many units of each product they want to buy. In that sense, our preferences are no less special or general than CES preferences. Furthermore, note that preferences in (1) are symmetric, i.e. no product is intrinsically better or worse than any other product. In other words, there is no explicit consumption hierarchy. This allows us to order products in ascending order from old to new, such that product $j$ was developed before product $j^{\prime}$, where $j^{\prime}>j .{ }^{4}$

The household's intertemporal objective function is given by

$$
U(0)=\int_{0}^{\infty} \exp (-\rho t) \log u\left(\{c(j, t)\}_{j=0}^{N(t)}\right) d t
$$

where $\rho>0$ denotes the time preference rate. Note that intertemporal preferences given by (2) are homothetic. Households maximize their lifetime utility (2) subject to non-negativity constraints $c(j, t) \geq 0$ for all $j, t$, and to their lifetime budget constraint

$$
\int_{0}^{\infty} \int_{0}^{N(t)} p(j, t) c(j, t) d j \exp \left(-\int_{0}^{t} r(s) d s\right) d t \leq a(0)+\int_{0}^{\infty}(w(t)+T(t)) \exp \left(-\int_{0}^{t} r(s) d s\right) d t
$$

\footnotetext{
${ }^{4}$ Note that the same ordering would emerge if we assumed instantaneous utility to take the following form $u(c(j, t))=\int j^{-\eta} c(j, t) d j$. The power function $j^{-\eta}$ implies that (instantaneous) marginal utility is falling in the index $j$, i.e. higher indexed goods yield lower marginal utility than lower indexed goods. The parameter $\eta \in(0,1)$ determines the "steepness" of the hierarchy, i.e. how fast marginal utility falls in index $j$. With these preferences households start consuming low-indexed goods (as they yield higher marginal utility) and expand consumption towards high-indexed goods until their income is used up. To keep the model simple, we will assume that such a hierarchy in consumption latently exists rather than explicitly modeling it. For a detailed discussion see Section 5.1.
} 
where $r(t)$ denotes the risk-free interest rate, $a(0)$ initial wealth, and $w(t)$ the market clearing wage rate. The solution to the household problem has been relegated to Appendix A.1. From the maximum principle conditions we derive the individual Marshallian demand function for product $j$ :

$$
c(j, t)= \begin{cases}1 & p(j, t) \leq z(j, t) \\ 0 & p(j, t)>z(j, t)\end{cases}
$$

where $z(j, t) \equiv[u(\cdot) \lambda(t)]^{-1}$ denotes the willingness to pay. Figure 1 below shows the individual demand curve (3) for product $j$. The costate variable $\lambda(t)$ can be interpreted as marginal utility of wealth at time $t$. Households purchase one unit of a product if the price of that product does not exceed their willingness to pay. Since preferences are symmetric over all products, the willingness to pay is identical for all products $j$. However, the willingness to pay depends on $\lambda(t)$, i.e. on the shadow price of (lifetime) income. Hence, consumption patterns differ across regions since by our distributional assumptions (lifetime) incomes are different across regions. Wealthy households in North, with a lower equilibrium value of $\lambda(t)$, consume a larger set of products than poor households in South.

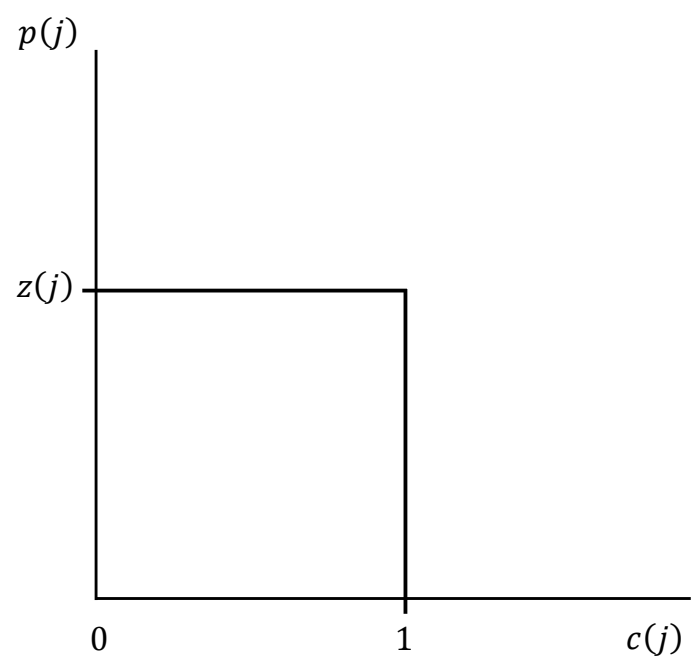

Figure 1: Individual demand

\subsection{Technology and trade integration}

\subsubsection{Innovation technology in North}

New products are designed and developed in high-income countries. ${ }^{5}$ Each firm in North is a single-product firm, which has access to the same innovation technology. The creation of a new

\footnotetext{
${ }^{5}$ In principle, one could think that both North and South have access to the innovation technology but that South is sufficiently unproductive at developing new products compared to North, such that in equilibrium no innovation takes place in South. Since it is difficult to measure research productivity, for illustration's sake, consider research input. World Bank (2014) data on research and development spending of low/middle and high income countries show that high income countries on average spent about 2.5 times as much on R\&D in percent of their GDP than low and middle income countries during the period 2000-2007.
} 
product requires $F^{N}(t)=F^{N} / N(t)$ units of labor, once this set-up cost has been incurred, the firm has access to a linear technology that requires $b^{N}(t)=b^{N} / N(t)$ units of labor to produce one unit of output, with $F^{N}, b^{N}>0$ being positive constants. Innovations obey an important spillover because they imply technical progress. We assume that the knowledge stock of this economy equals the number of known designs $N(t)$. The labor input coefficients are inversely related to the stock of knowledge. New products are protected by infinite patents but face a positive probability of being copied by a Southern firm (i.e. patent infringement). We assume that firms in North cannot license technology to Southern firms, or set up manufacturing plants in South (i.e. engage in foreign direct investment).

\subsubsection{Imitation technology in South and transportation costs}

As in Grossman and Helpman (1991), we assume that each new product, which has been developed in North at time $t$, faces the same positive probability of being imitated by a Southern firm at some time $\tilde{t}>t$. At the time the product is developed, date $\tilde{t}$ is unknown. In other words, $\widetilde{t}$ is a random variable that represents the age of a product at the time of imitation. A Southern firm selects at random one of the existing products in North, which has not yet been copied, for imitation. We assume that firms in South benefit in reverse engineering and production from the total stock of knowledge (i.e. there are international knowledge spillovers). Imitation of a selected product requires $F^{S}(t)=F^{S} / N(t)$ units of labor, with $F^{S}>0$. Investing $F^{S}(t)$ allows a Southern firm to learn the production process of the randomly chosen product with probability one. Hence, there is complete certainty for a Southern imitator that reverse engineering succeeds. Subsequent production of the copied good requires $b^{S}(t)=b^{S} / N(t)$ units of labor per unit. Finally, we assume that product markets are fully integrated and trade costs are zero.

\subsection{Equilibrium}

Depending on parameter values, two decentralized equilibria can emerge: (i) households in South are too poor to afford any Northern products or (ii) they can afford at least some Northern products. In case (i) no trade equilibrium exists. Hence, we focus on the interesting case (ii), and assume in the following that households in South can afford some Northern products. In proving the existence of the equilibrium, we will derive the necessary assumption on parameters. Let us denote the set of all products available in the economy as $N(t)=$ $N^{N}(t)+N^{S}(t)$, where $N^{N}(t)$ denotes the subset of products that have not yet been imitated by South, and $N^{S}(t)$ the subset of products that have been copied by South.

\subsubsection{World demand}

In the equilibrium we consider households in North consume all products available in the market $N_{N}(t)=N(t)$, whereas households in South consume only a subset of all products $N_{S}(t) \subset$ $N(t)$, which includes all products manufactured in South and some but not all Northern 
products. World demand for product $j$ can be derived by horizontally aggregating individual demand (3) across regions. It is determined by:

$$
C(j, t)= \begin{cases}0, & p(j, t)>z_{N}(j, t) \\ (1-\beta) L, & z_{S}(j, t)<p(j, t) \leq z_{N}(j, t) \\ L, & p(j, t) \leq z_{S}(j, t)\end{cases}
$$

where $z_{i}(j, t)$, with $i \in\{N, S\}$, denotes the willingness to pay of households in North and South, respectively. Since the willingness to pay is the same for all products $j$, aggregate demand is the same for all products. World demand (4) is depicted in Figure 2 below.

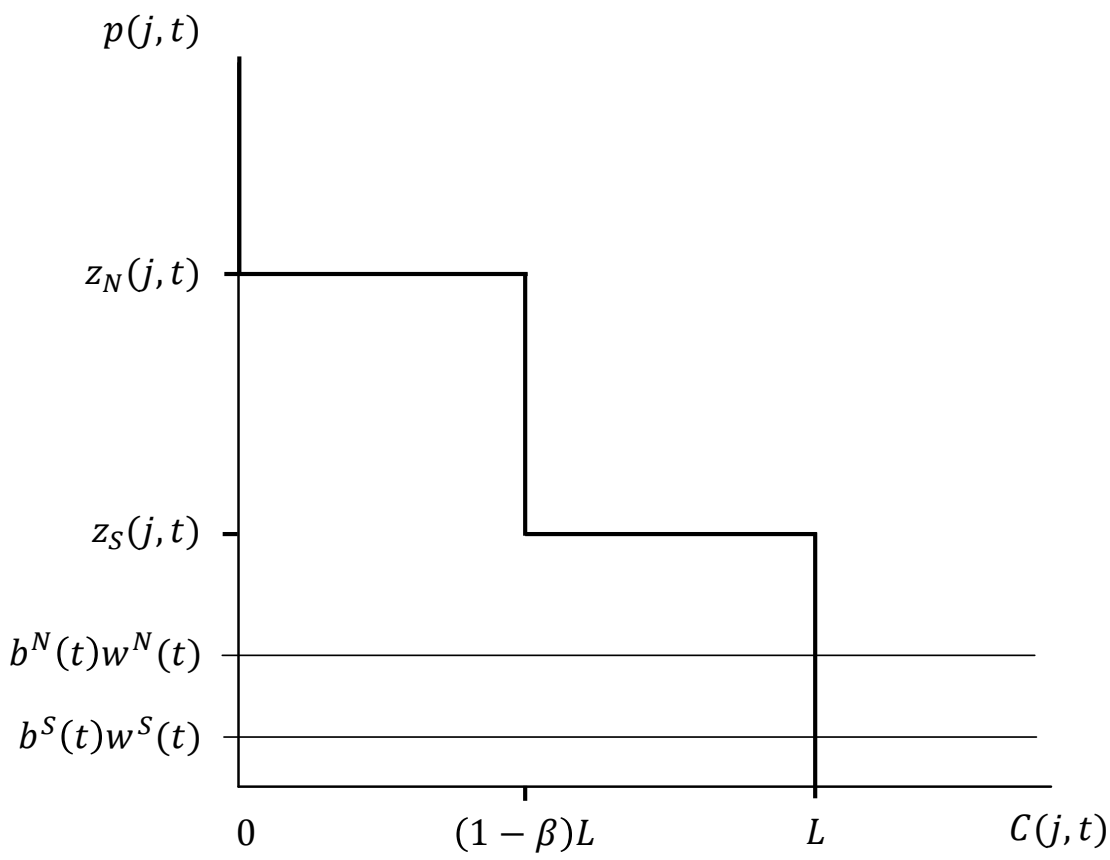

Figure 2: World demand

If the price of a product exceeds the willingness to pay of Northern households, there is no demand for that product. With a price between the willingness to pay of Southern and Northern households only the latter purchase the product. If the price falls short of the willingness to pay of households in South everyone purchases it. Figure 2 is drawn under the assumption that the willingness to pay of Southern households exceeds marginal costs $b^{N}(t) w^{N}(t)$, which holds true in the equilibrium of interest.

\subsubsection{Aggregate supply}

Let us first consider the problem of a monopolistic firm $j$ located in North. Firm $j$ maximizes operating profits

$$
\pi^{N}(j, t)=\left[p(j, t)-w^{N}(t) b^{N}(t)\right] C(j, t)
$$


subject to aggregate demand (4) by choosing a price $p(j, t)$ such that marginal revenue equals marginal cost. From Figure 2 and the discussion in the previous section it follows that there are two candidates for the price that maximizes profits (5). Firm $j$ either sets a high price equal to the willingness to pay of Northern households $z_{N}(j, t)$ and sells exclusively to domestic households, or it sets a low price equal to the willingness to pay of Southern households $z_{S}(j, t)$ and serves both markets.

We assume that firms cannot price discriminate across regions. As there are no trade costs, arbitrageurs would take advantage of any price differential between North and South. ${ }^{6}$ Thus, exporters set the same price in both regions. This implies that in equilibrium not all Northern firms export. To see this, suppose that at every point in time all Northern firms would set prices equal to the willingness to pay of Southern households and sell to everyone. In that case, households in North would not exhaust their budgets, i.e. the shadow price of their (lifetime) income would become zero. That would imply an infinitely large willingness to pay for an additional product. Consequently, Northern firms had an incentive to deviate from selling to everyone and sell exclusively in North. However, a situation where all Northern firms serve all households cannot be an equilibrium. Also, by the same argument, a situation where all Northern firms sell exclusively to Northern households cannot be an equilibrium as the willingness to pay of Southern households for a Northern product would become infinitely large.

In an equilibrium, where some Northern firms serve all households in both regions and others serve exclusively the domestic region, firms must be indifferent between selling only to Northern households and selling to all households at any point in time. Hence, the following arbitrage condition must hold

$$
\left[z_{N}(j, t)-w^{N}(t) b^{N}(t)\right](1-\beta) L=\left[z_{S}(j, t)-w^{N}(t) b^{N}(t)\right] L
$$

In the aggregate, a measure $n$ of firms sells in both North and South whereas $(1-n)$ firms sell only in North. Due to symmetric preferences, however, the behavior of a single firm is indeterminate. Because we are free to order the different goods, we may think of the following firm behavior at the micro level that generates the described outcome at the macro level: After developing a new product each firm starts marketing its product solely in North and after a certain period of time has elapsed, i.e. the time it takes for incomes in South to have grown sufficiently, begins exporting. In that case, there are at any point in time new products that are sold exclusively in the domestic market and older products that are exported as well. Section 5 discusses two possible extensions where the product cycle at the firm level is determinate. We argue that while the model would become substantially more complex, the basic structure and intuition of the baseline model is preserved.

The Northern firm, which develops product $j$ at time $t$, faces a positive probability that its

\footnotetext{
${ }^{6}$ The threat of arbitrage opportunities imposes a price setting restriction on firms. If there are no trade costs the price setting restriction is always binding. However, in the presence of iceberg trade costs the price setting restriction might not be binding. In particular, if the difference in per capita incomes between North and South were sufficiently low, all newly invented products would be exported to South right away.
} 
product will be copied by a Southern firm. After a product has been imitated, the Southern firm maximizes operating profits

$$
\pi^{S}(j, t)=\left[p(j, t)-w^{S}(t) b^{S}(t)\right] C(j, t)
$$

where $C(j, t)=L$ is given by (4). After the firm in South has copied the Northern product $j$ it enters into price competition with the Northern firm currently producing $j$ (i.e. the innovating firm). This forces the Southern firm to set a limit price equal to the marginal costs of the competing firm in North. Hence, optimal prices of Southern products are equal to $w^{N}(t) b^{N}(t) .^{7}$

\subsubsection{Labor markets}

Labor is immobile across regions but regional labor markets are assumed to be perfect. In particular, in North labor is completely mobile between production and R\&D, and in South between production and reverse engineering. Labor market clearing in North demands that

$$
(1-\beta) L=g(t) F^{N}+b^{N} L[n(t)-m(t)]+(1-\beta) b^{N} L[1-n(t)]
$$

where we defined $g(t) \equiv \dot{N}(t) / N(t)$, and the share of goods consumed and produced in South, respectively, as $n(t) \equiv N_{S}(t) / N(t)$ and $m(t) \equiv N^{S}(t) / N(t)$. The first term in (7) on the right-hand side denotes labor demand from the $\mathrm{R} \& \mathrm{D}$ sector, the second term labor demand from the production of older Northern products consumed by all households in both regions, and the third term labor demand from the production of newer Northern products exclusively consumed by Northern households. Similarly, labor market clearing in South requires

$$
\beta L=g^{S}(t) m(t) F^{S}+m(t) b^{S} L
$$

where we defined $g^{S}(t) \equiv \dot{N}^{S}(t) / N^{S}(t)$. The right-hand side in (8) denotes labor demand from reverse engineering, and production of imitated products which are consumed by all households in both regions.

\subsubsection{Capital markets}

We assume that international capital markets are perfect, hence, interest rates equalize across regions. The expected present discounted value of profits of product $j$ that was introduced at time $t$ is determined by equation (9) below, given the instantaneous rate of imitation $\mu(t) \equiv$ $\dot{N}^{S}(t) / N^{N}(t)$. We make the standard assumption of free entry into product development in

\footnotetext{
${ }^{7}$ The wide-gap case discussed in Grossman and Helpman (1991) where Southern firms can set the monopoly price cannot occur here since $z_{S}(t)>w^{N}(t) b^{N}(t)>w^{S}(t) b^{S}(t)$ in equilibrium, as otherwise no firm in North would export to South. Our case is similar to their narrow-gap case, where Southern firms charge prices marginally below the marginal cost of Northern firms.
} 
North. Hence, the expected value of product $j$ must equal R\&D costs $w^{N}(t) F(t)$,

$$
v^{N}(j, t)=\int_{t}^{\infty} \exp \left(-\int_{t}^{s}(r(\tau)+\mu(\tau)) d \tau\right) \pi^{N}(j, s) d s=w^{N}(t) F^{N}(t) .
$$

Note that profits are discounted using the risk-adjusted interest rate $r(\tau)+\mu(\tau)$, where $r(\tau)$ is the risk-free interest rate and $\mu(\tau)$ the risk premium. Since we assume capital markets to be perfect, households can diversify away the idiosyncratic risk of a Northern firm of being copied by holding a portfolio of shares in all Northern firms. Free entry also prevails in the reverse engineering sector in South, which is not an uncertain activity, so that their present discounted value of profits $v^{S}(j, t)$ must equal the imitation cost $w^{S}(t) F^{S}(t)$,

$$
v^{S}(j, t)=\int_{t}^{\infty} \exp \left(-\int_{t}^{s} r(\tau) d \tau\right) \pi^{S}(j, s) d s=w^{S}(t) F^{S}(t) .
$$

\subsubsection{Asset holdings and balance of payments}

The balance of payments in present value terms is determined by

$$
\begin{aligned}
0 & =\int_{0}^{\infty}\left\{\left[(1-\beta) L N^{S}(t) w^{N}(t) b^{N}(t)-\beta L\left(N_{S}(t)-N^{S}(t)\right) z_{S}(t)\right]\right. \\
& \left.+\beta L T_{S}(t)\right\} \exp \left(-\int_{0}^{t} r(s) d s\right) d t
\end{aligned}
$$

where the first term in brackets on the right-hand side denotes the trade balance and the second term net transfer payments. We assume that net foreign assets (portfolio investments) are zero. ${ }^{8}$ Note that if $T_{S}(t)>0$ for all $t$, the South runs a (permanent) trade deficit, i.e. the value of its exports falls short of the value of its imports.

\subsection{Steady state}

The economy is in a steady state if Northern firms introduce new products at a constant rate $g$ and Southern firms imitate at a constant rate $\mu$. In steady state, shares of resources devoted to $\mathrm{R} \& \mathrm{D}$ and production are constant, and the fraction of Northern products that have not yet been imitated is constant. Furthermore, prices of Northern and Southern products and therefore, profits of Northern firms are constant. Let us choose the marginal costs of production of Northern firms as the numeraire, and set $w^{N}(t) b^{N}(t)=1$ for all $t$.

First, we turn to the first-order conditions of the household's maximization problem. It follows that the optimal evolution of consumption of Northern and Southern households, i.e. the Euler equation, in steady state is given by

$$
g=r-\rho
$$

\footnotetext{
${ }^{8}$ Because of equal interest rates, consumption growth is identical across regions in steady state. Hence, net foreign assets will remain zero forever. If net foreign assets are non-zero, $T_{S}$ is to be interpreted as sum of transfer and interest payments. For a formal derivation of the balance of payments see Appendix A.4.
} 
which implies equal growth rates in North and South. Households budget constraints in steady state are given in Appendix A.3.

Now, consider the equilibrium in the labor markets. The resource constraint in South (8) becomes

$$
\beta L=g m F^{S}+m b^{S} L .
$$

A higher fraction of products that have been imitated $m$ implies that there is more imitation activity in South so that on average Northern products are copied sooner, ceteris paribus. This tends to depress innovation activity in North implying a lower $g$. The resource constraint of North (7) can be written as follows in the steady state

$$
(1-\beta) L=g F^{N}+L b^{N}(n-m)+(1-\beta) L b^{N}(1-n)
$$

where $n$ denotes the "consumption gap" between South and North. Note that a higher share of South in total production $m$ releases resources from the production sector in North that can be reallocated to the $\mathrm{R} \& \mathrm{D}$ sector, ceteris paribus. This allows North to introduce new products at a higher rate $g$. Furthermore, a higher consumption share of South $n$ induces a reallocation from the $R \& D$ sector to the production sector in North to satisfy the additional demand for existing Northern products by South, thereby depressing innovation in North, ceteris paribus.

Next, a fixed inter-sectoral allocation of labor implies that prices of Northern products must be constant in steady state. We denote the price of a new product that is sold exclusively to Northern households as $z_{N}$. Since all firms face the same demand curve and have the same cost structure, $z_{N}$ is identical for all new products $j \in\left(N_{S}(t), N(t)\right]$. From the arbitrage condition (6) follows that prices for all old Northern goods $j \in\left(N^{S}(t), N_{S}(t)\right]$, which are sold to all households, are also constant and determined by $z_{S}=\beta+(1-\beta) z_{N}$. Moreover, this implies that profits are constant over time. Prices of Southern products $w^{N}(t) b^{N}(t)$ are equal to 1 due to our choice of numeraire. This is consistent with the steady state, else demand for Southern labor would change over time.

Let us consider the average life cycle in steady state of some product $j$, which is introduced at time $t$. At the time of introduction product $j$ is sold at price $z_{N}$ exclusively to Northern households. At time $t+\Delta$, where $N(t)=N_{S}(t+\Delta)=N_{S}(t) \exp (g \Delta)$, the Northern firm producing good $j$ lowers the price to $\beta+(1-\beta) z_{N}$ and exports it to South. Therefore, the average demand lag equals $\Delta=-\log (n) / g>0$, decreasing in the consumption share $n$ and the innovation rate $g$. We consider the case where $\tilde{t}>t+\Delta$ for all $t$. In other words, on average Northern products are exported to South for some time before they are copied by a Southern firm. ${ }^{9}$ Notice that in steady state $\widetilde{t}$ follows an exponential distribution. Thus, the average time span product $j$ is being produced in North is determined by $1 / \mu$. Hence, our assumption above implies that the demand lag is shorter than the time span product $j$ is being manufactured in North, i.e. $1 / \mu>\Delta$. Due to lower production costs in South, Southern firms can set a price marginally below 1 , the marginal costs of Northern firms. Hence, the Northern

\footnotetext{
${ }^{9}$ Note that in the other case with $\widetilde{t} \leq t+\Delta$, goods would on average skip the export stage. We consider the case in the text to be the relevant one, i.e. the one consistent with the product cycle hypothesis.
} 
firm stops producing product $j$ and the product is now exported to North. Of course, this discussion is only relevant for the average product. By the random nature of imitation there will be some products that skip the export stage (i.e. those products become "prematurely old"). The average life cycle of some product $j$ in terms of sales volume is depicted in Figure 3 below.

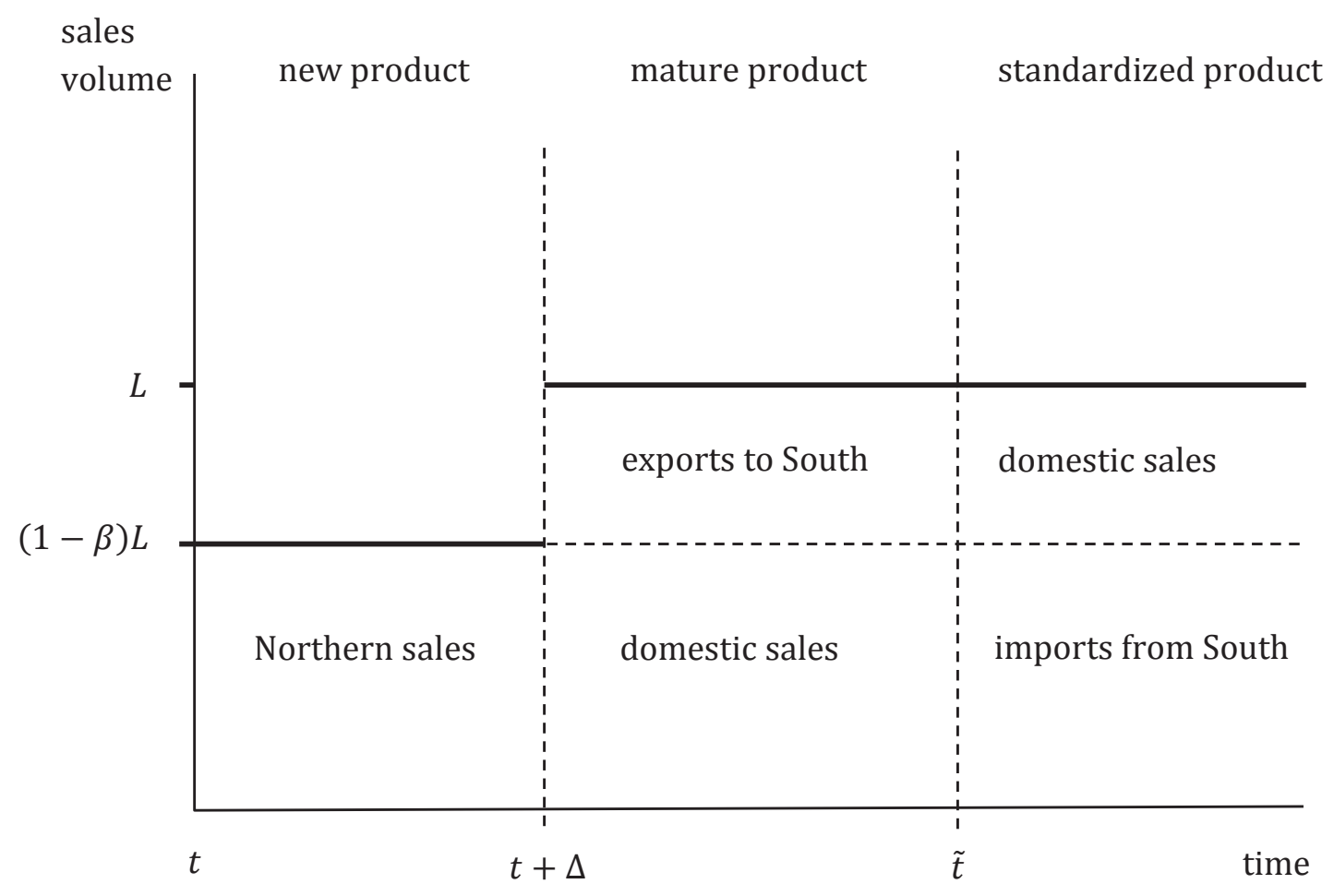

Figure 3: Average life cycle (in terms of sales volume)

From the definition of the imitation rate $\mu=\dot{N}^{S}(t) / N^{N}(t)$, we can express the production share of South in the total number of differentiated products as

$$
m=\frac{\mu}{g+\mu}
$$

which must be constant in the steady state. Next, the zero-profit condition (9) together with the arbitrage condition (6) in North implies that in the steady state the value of a firm is equal to the expected present discounted value of its future profits

$$
\frac{\left[z_{N}-1\right](1-\beta) L}{r+\mu}=\frac{F^{N}}{b^{N}}
$$

Similarly, in South the zero-profit condition (10) yields

$$
\frac{\left[1-\omega^{S} b^{S}\right] L}{r}=\omega^{S} F^{S}
$$


where $\omega^{S}(t) \equiv w^{S}(t) / N(t)$ is constant since wages in South grow at rate $g$. Last, in steady state, the balance of payments (11) becomes

$$
(n-m)\left[\beta+(1-\beta) z_{N}\right] \beta=m(1-\beta)+\beta T
$$

where $T \equiv T_{S}(t) / N(t)$. Note that due to Walras' law the balance of payments is implied by the budget constraints, the zero-profit conditions and the resource constraints.

Equations (12) - (18) in the unknowns $g, \mu, n, m, r, z_{N}$, and $\omega^{S}$ fully characterize the steady state. We can reduce this system to 2 equations in 2 unknowns $m$ and $g$. The first equation, the $R S$-curve, describes a steady state relationship between $g$ and $m$ that is consistent with labor market clearing in South:

$$
m=\frac{\beta L}{g F^{S}+b^{S} L} .
$$

The second equation, the $N A$-curve, describes a steady state relationship between $g$ and $m$ that is consistent with labor market clearing in North, the balance of payments, free entry in North, and the no arbitrage condition

$$
\left(1+\rho \frac{F^{N}}{b^{N} L}+\frac{g}{1-m} \frac{F^{N}}{b^{N} L}\right)\left((1-\beta)\left(\frac{1}{b^{N}}-1+m\right)-g \frac{F^{N}}{b^{N} L}\right)=m(1-\beta)+\beta T .
$$

To guarantee that the $N A$-curve defined by (20) has a positive $x$-axis intercept in the $(m, g)$ space we make the following assumption.

Assumption 1. $\left(1+\rho \frac{F^{N}}{b^{N} L}\right)(1-\beta)\left(\frac{1}{b^{N}}-1\right) \geq \beta T \geq 0$.

Proposition 1. Given Assumption 1 holds, a steady state equilibrium with positive growth rate $g$ and a constant share of imitated products $m$ exists.

Proof. The RS-curve (19) is downward sloping in the $(m, g)$-space. To determine the shape of the $N A$-curve we rewrite $(20)$ as $N A(m, g)=0$. The left hand side of this equation is a quadratic function in $g$ with inverted U-shape. If Assumption 1 holds, $N A(m, g)$ has a negative and a positive solution for $g$. Thus, $N A_{g}(m, g)<0$ at the relevant solution. Further, differentiation shows that $N A_{m}(m, g)=\frac{g}{(1-m)^{2}} \frac{F^{N}}{b^{N} L}\left((1-\beta)\left(\frac{1}{b^{N}}-1+m\right)-g \frac{F^{N}}{b^{N} L}\right)+$ $\left(\rho \frac{F^{N}}{b^{N} L}+\frac{g}{1-m} \frac{F^{N}}{b^{N} L}\right)(1-\beta)>0$. Hence, the $N A$-curve has a positive slope and positive intercept with the $x$-axis and a negative intercept with the $y$-axis in the $(m, g)$-space. Figure 4 below depicts the graphical solution of the steady state. ${ }^{10}$

\subsection{Transitional dynamics}

The transitional dynamics are easy to characterize. The full derivation of the transitional dynamics, including a phase plane illustrating the dynamics, is given in Appendix A.2. If we

\footnotetext{
${ }^{10}$ Note that the y-axis intercept $\left.m\right|_{g=0}$ implied by $\left.N A\right|_{g=0}$ is given by $m=-\frac{\left(1+\rho \frac{F^{N}}{b^{N} L}\right)(1-\beta)\left(\frac{1}{b^{N}}-1\right)-\beta T}{\rho(1-\beta) \frac{F^{N}}{b^{N} L}}<0$ due to Assumption 1.
} 


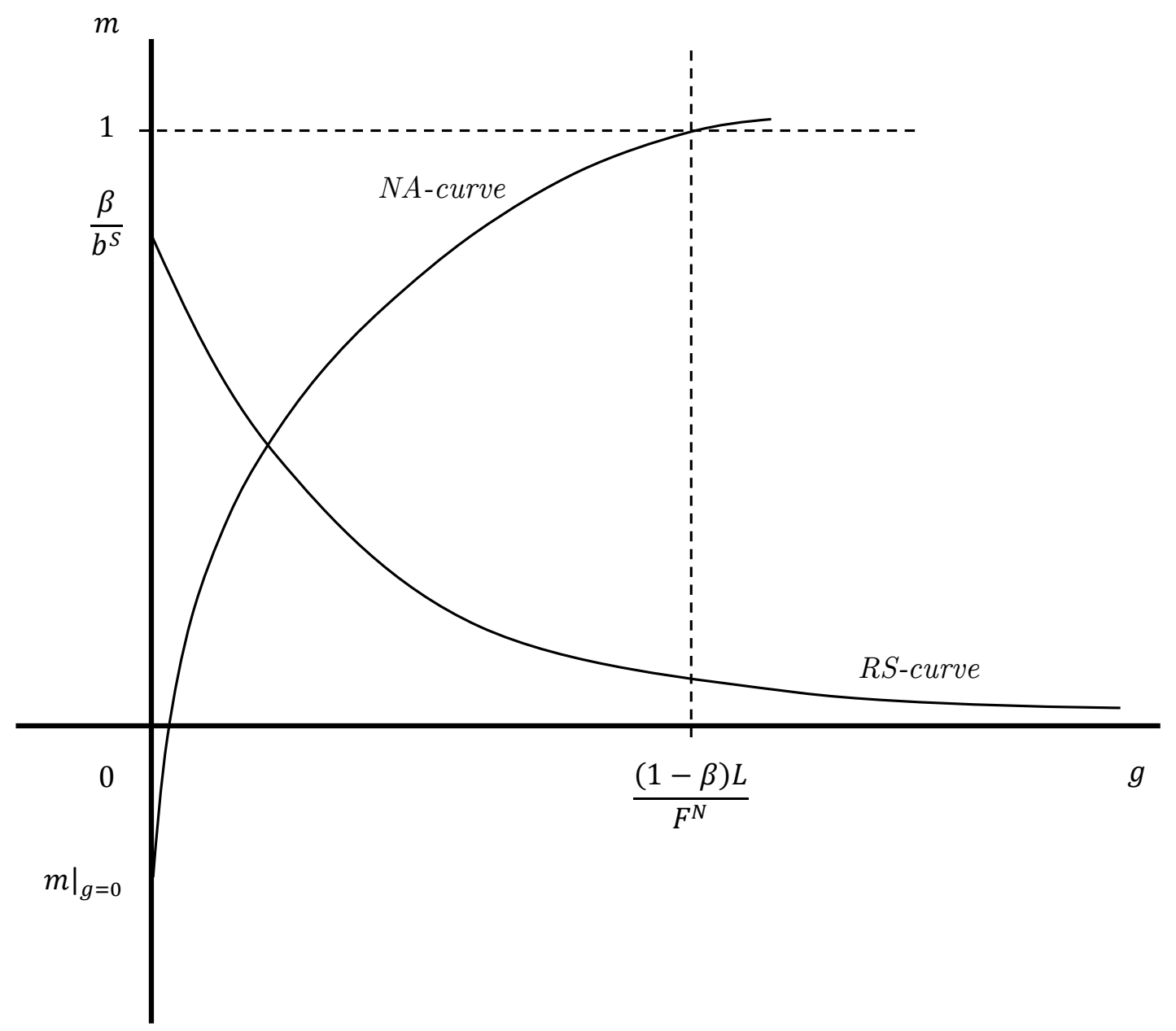

Figure 4: Steady state

replace $g$ with $g^{S}$ on the x-axis in Figure 4, the $R S$-curve now determined by equation (8), representing the Southern full employment condition only, must hold also outside the steady state. Hence, along a transition path, $m$ and $g^{S}$ move along the $R S$-curve. The $N A$-curve (20), instead, is a steady state condition. Appendix A.2 demonstrates that the steady state is sattlepath stable. When the number of industries in South is below its steady state value, $m(0)<m$, then $\dot{m} / m=g^{S}-g>0$, i.e. the growth rate of imitation is higher than the growth rate of innovation during the transition process. Thus, $m$ converges monotonically to its steady state value.

\subsection{Limit case: Costless reverse engineering}

To understand the mechanics at work it is instructive to assume, albeit less realistically, that reverse engineering is costless, i.e. $F^{S} \rightarrow 0$. As $F^{S} \rightarrow 0$ the $R S$-curve rotates upwards and becomes a horizontal line at $m=\beta / b^{S}<1$. Since the $N A$-curve is independent of $F^{S}$, the growth rate $g$ and the Southern imitation share $m$ increase as $F^{S} \rightarrow 0$. The intuition is that if 
imitation becomes costless, South can take over the maximal share of production from North. This releases resources in North that can be allocated to the research and development of new products. At the same time, the imitation activity is at its maximum in South (only restricted by limited resources), which means that the risk-adjusted interest rate peaks, depressing the present discounted value of profits earned from creating new products. In equilibrium, the first effect dominates the second one, and $g$ reaches its maximum.

\section{Changing gap between North and South}

How will the product cycle and therefore the international division of production and long-run innovation incentives change when the gap between North and South changes? In this section, we consider the cases of a rise in labor productivity in South, a larger Southern population, and an increased net wealth position of South in turn, and explore their steady state effects. A special focus lies on the implications on the length of the three product cycle stages, which are discussed at the end of each subsection. Simulated comparative statics results are relegated to Appendix A.5. ${ }^{11}$ In Section 3.4, we further highlight the difference between non-homothetic and homothetic preferences by comparing the results from our model to those of Grossman and Helpman (1991).

\subsection{Increase in Southern labor productivity}

In recent years, relative productivity of the South has risen. Jorgenson and Vu (2011) mention that "while labor has become nearly twice as productive over the last 20 years worldwide it has risen even more so in the developing countries, with Asia in the lead." According to McMillan and Rodrik (2011) labor productivity growth in Asian countries between 1990-2005 was on average $3.87 \%$, compared to $1.46 \%$ in high income countries. This poses the natural question of how changes in labor productivity in South affect the product cycle.

Proposition 2. An increase in Southern productivity, i.e. a decrease in $b^{S}$ or $F^{S}$, results in a higher growth rate $g$, Southern imitation share $m$ and imitation rate $\mu$. Hence, the average time span a product is being manufactured in North $1 / \mu$ becomes shorter. While the terms of trade move in favor of North ( $z_{S}$ increases), two opposing effects move relative wages and the consumption share. Higher Southern productivity tends to increase Southern relative wages while the higher growth rate $g$ tends to decrease them. A higher imitation rate expands the Southern consumption share whereas the higher growth rate lowers it.

Proof. A decrease in $b^{S}$ shifts the $R S$-curve upwards, whereas a decrease in $F^{S}$ rotates the $R S$-curve upwards, both leaving the $N A$-curve unaffected. Hence, both a decrease in $b^{S}$ and $F^{S}$ lead to a higher growth rate $g$ and Southern imitation and consumption share $m$. The imitation rate increases, as $\mu$ depends positively on $g$ and $m$. According to the Northern zero

\footnotetext{
${ }^{11}$ Note that the wage rate of North relative to South is determined by $w^{N}(t) / w^{S}(t)=\left(\omega^{S} b^{N}\right)^{-1}$, where $\omega^{S}=\left(b^{S}+(\rho+g) F^{S} / L\right)^{-1}$ is pinned down by (17). Using the zero-profit condition (16) and the arbitrage condition in North, we get an expression for the terms of trade of North, $z_{S}=1+[\rho+g /(1-m)] F^{N} / b^{N} L$.
} 
profit condition (16) $z_{N}$ and $z_{S}$ both increase. Using the Southern zero profit condition (17) we see that $\omega^{S}$ increases with higher productivity in South but decreases in $g$. This implies that relative wages $w^{N}(t) / w^{S}(t)$ decrease due to the direct productivity effect and increase because of a higher growth rate. Using the Northern resource constraint, we see that a higher $g$ reduces $n$ while the higher $m$ raises $n$.

Intuitively, a reduction in $F^{S}$ or $b^{S}$ triggers more imitation because it is cheaper to produce imitated goods. Thus, the imitation rate $\mu$ and the share of products manufactured in South $m$ rise, ceteris paribus. On the one hand, the higher risk-adjusted interest rate $r+\mu$ lowers the present discounted value of profits earned from innovation. On the other hand, as the set $m$ of cheap products produced in South expands the (real) income of households in both regions increases, which translates into a higher willingness to pay for both $\left(z_{S}\right.$ and $z_{N}$ increase). The higher willingness to pay of Southern households implies that they can afford to buy more new products manufactured in North ( $n$ rises). Second, the higher willingness to pay of households in North makes the innovation of new products more attractive. The positive effect on the present discounted value of profits through higher prices $z_{N}$ dominates the negative effect of a higher risk-premium $\mu$ such that the innovation rate $g$ rises. ${ }^{12}$ Still, the imitation rate $\mu$ goes up more than the innovation rate, hence $m$ rises.

Looking at relative wages, the increase in Southern labor productivity directly increases the wage rate $\omega^{S}$, holding $g$ constant. Moreover, there is also an indirect effect through the increase in $g$, which leads to an increase in the interest rate $r$, and therefore to a decrease in the present discounted value of profits earned from copying Northern products. The indirect effect induces less firms to enter the market in South, depressing labor demand, and hence the wage rate $\omega^{S}$. In the simulations the first effect dominates such that the Northern relative wage rate $w^{N}(t) / w^{S}(t)$ falls.

\section{The effect on the product life-cycle}

The time length $\Delta$ where products are exclusively sold in North becomes shorter due to two reasons: households in South are relatively richer ( $n$ rises) and the overall growth rate $g$ is higher. Since the imitation rate $\mu$ increases, the average time span a product is being manufactured in North $1 / \mu$ becomes shorter as well. The third stage during which North imports a product clearly increases. The time period during which North exports a product $(1 / \mu-\Delta)$ decreases according to our simulations.

\subsection{Increase in Southern population}

The entry of China into the world market in the 1980s can be seen as a rapid expansion of the Southern population. A fortiori, developing countries show higher population growth rates

\footnotetext{
${ }^{12}$ Alternatively, this can be seen from the labor market clearing condition in North. A marginal increase in $n$ leads to an increase in labor demand in North's production sector by $b^{N} \beta L$, whereas a marginal increase in $m$ leads to a decrease in labor demand of $b^{N} L$. Since we assume $\beta<1$, it is straightforward to see that the latter effect outweighs the former, leaving more resources available in North to be reallocated to the R\&D sector.
} 
than developed countries. The World Bank (2014) reports a population growth rate for low and middle income countries of approx. $1.3 \%$ p.a. and for high income countries of approx. $0.6 \%$ p.a. for the period of 2002-2013. Those events and developments raise the question what are the consequences of a larger Southern population on the product cycle.

An increase in Southern population has very similar effects as the productivity changes discussed above. Here, the comparative statics are much more complex as not only the $R S$-curve shifts upwards but also the $N A$-curve shifts to the left. While the effects on $m$ are clearly positive, our simulations show that for a wide range of parameter values, the innovation rate increases with higher Southern population. Only for an extremely unproductive South the negative effect on $g$ starts to dominate for large values of $\beta$.

Proposition 3. A higher Southern population, while leaving Northern population $(1-\beta) L$ constant, increases the imitation rate. The effect on the innovation share is ambiguous.

Proof. A higher Southern population share, leaving $(1-\beta) L$ constant, leads to an upward shift of the $R S$-curve. For any given $m \in(0,1)$, the $N A$-curve shifts to the left. This can be easily shown by total differentiation of $N A(m, g ; \beta)=0$. In Proposition 1 we showed that $N A_{g}(m, g)<0$ and $N A_{m}(m, g)>0$ at the relevant solution. We get $N A_{\beta}(m, g)=$ $-\left(\rho \frac{F^{N}}{b^{N} c}+\frac{g}{1-m} \frac{F^{N}}{b^{N} c}\right)(1-\beta)\left(\frac{1}{b^{N}}-1+m-g \frac{F^{N}}{b^{N} c}\right)-\frac{1}{1-\beta} T<0$.

Higher population in South increases demand for existing products and resources in South for imitating Northern products and for producing imitated goods. Thus, the imitation rate $\mu$ and the share of products manufactured in South $m$ rise, ceteris paribus. On the one hand, this releases resources in North for innovation. On the other hand, the higher risk-adjusted interest rate $r+\mu$ lowers the present discounted value of profits earned from innovation. As the set $m$ of cheap products produced in South expands, the (real) income of households increases, which translates into a higher consumption share in South ( $n$ rises). The higher willingness to pay of households in North makes the innovation of new products more attractive. Our simulations show that the positive effect on the present discounted value of profits through higher prices $z_{N}$ dominates the negative effect of a higher risk-premium $\mu$ such that the innovation rate $g$ rises. According to our simulations with $T=0, g$ starts to decline for a higher $\beta$ only if South is extremely unproductive. In the case of positive transfer from North to South $(T>0)$, the negative effect on $g$ starts to dominate already for much lower productivity levels (i.e. South is only relatively unproductive compared to North).

\section{The effect on the product life-cycle}

Our simulations show that the effect on the product life-cycle are similar to the productivity case discussed above. Both the time length $\Delta$ where products are exclusively sold in North and the average time span a product is being manufactured in North $1 / \mu$ become shorter. The third stage during which North imports a product therefore increases. The time period during which North exports a product $(1 / \mu-\Delta)$ decreases. 


\subsection{Changes in income inequality across regions}

Our model can be used to understand the impact of macroeconomic imbalances on the international divison of production. Public attention has mostly focused on the large persistent current account deficits of the United States and the increasing current account surpluses of China (Lane and Milesi-Ferretti 2007a). Since the early 2000s the net foreign asset position of industrial countries as a whole, and the United States in particular, has deteriorated, whereas for developing countries it has improved (Lane and Milesi-Ferretti 2007b). While the net foreign asset position is exogenous to our model we may ask what are the effects on the product cycle of net wealth transfers from North to South.

Proposition 4. An increase in $T$, i.e. lowering world income inequality, leads to a new steady state where the growth rate $g$ is lower and the share of imitated and consumed products, $m$ and $n$, are higher. Northern relative wages deteriorate. There are opposing effects on the terms of trade and on the three stages of the product life cycle.

Proof. An increase in $T$ leads to an upward shift of the $N A$-curve since $\left.N A\right|_{g=0}$ is a positive function of $T$. Notice that $g$ implied by the $N A$-curve as $m \rightarrow 1$ is given by $g=(1-\beta) L / F^{N}$, independent of $T$. As the $R S$-curve is unaffected by a change in $T$, the new steady state has a lower $g$ and higher $m$. Using the Northern resource constraint, we see that a lower $g$ together with a higher $m$ increases $n$. Since $\omega^{S}$ is a decreasing function of $g$, Northern relative wages $w^{N}(t) / w^{S}(t)=\left(\omega^{S} b^{N}\right)^{-1}$ are lower. A lower $g$ tends to decrease the terms of trade $z_{S}$, whereas a higher $m$ tends to increase them.

A higher transfer leads to higher incomes in South and lower incomes in North, ceteris paribus. Lower incomes in North depress the incentives to develop a new product, which decreases the innovation rate $g$. As Southern resources are fixed, the fraction of imitated products increase. At the same time, higher incomes in South translate into a higher willingness to pay for older products produced in North. This implies that profits of innovating firms in North from selling only to Northern households fall short of profits from selling to all households, creating a disequilibrium in North. This induces some Northern firms to start exporting. As Southern households consume more products, i.e. $N_{S}(t)$ increases, their marginal willingness to pay, ceteris paribus, decreases until the equilibrium in North is restored. In the new equilibrium, households in South consume a higher fraction of all products $n$, and their (marginal) willingness to pay is lower. In our simulations, North's export prices $z_{S}$ decrease, and as North's import prices are equal to one, the terms of trade move in favor of South. ${ }^{13}$

\section{Effect on product life-cycle}

There are two opposing effects on the the first stage of the product cycle (the demand lag $\Delta$ ). On the one hand, households in the South are richer so that the Northern firm producing the

\footnotetext{
${ }^{13}$ Totally differentiating the Northern zero-profit condition (16) and the definition of the imitation rate (15) shows that $d z_{N}>0$ and $d \mu<0$ if and only if $\beta /\left(\beta-b^{S} m\right)>m /(1-m)>b^{S} L / F^{S}$, where $\beta / b^{S}>m$ and we used that along the $R S$-curve $d m / d g<0$. Sufficient conditions are $m<0.5$ and $b^{S} L / F^{S}<1$.
} 
latest product would like to export sooner (effect of higher $n$ ). On the other hand, even though the level of income for Southern households is higher, their income grows at a lower rate. This induces the Northern producer of the latest product to export later (effect of lower $g$ ). The simulations show that the first effect dominates so that the first stage, where new products are exclusively sold in the North, becomes shorter. There are two opposing effects on the second stage of the product cycle. On the one hand, the imitation rate $\mu$ decreases because of a lower growth rate $g$. On the other hand, the higher share of imitation increases $\mu$. In our simulations the effect of a lower growth rate dominates. Hence, the average time span a product is being manufactured in the North $1 / \mu$ becomes longer so that the third stage during which the North imports a product decreases. Moreover, the time period during which the North exports a product $(1 / \mu-\Delta)$ becomes longer.

\subsection{Comparison to CES utility case}

This subsection summarizes the contribution of non-homothetic preferences to a theory of product cycles. There are two main differences to the CES case. Homothetic separable CES preferences yield an incomplete product cycle only. There is no first stage where the product is exclusively produced and consumed in North. As the reservation price is infinite, a consumer always buys all goods, irrespective her income and product adoption is uncorrelated with per capita income. This leads us to the second difference. With non-homethetic preferences, income differences affect the average time span of all three product cycle stages. Hence, net wealth positions affect the product cycle. Clearly, with CES preferences a transfer from rich North to poor South has no effects on innovation incentives.

To better understand the intuition of our model and the role of non-homothetic preferences, we compare our results with Grossman and Helpman (1991), henceforth referred to as GH. Although our model and GH are not exactly nested, the models are similarly structured which allows to compare the mechanisms. Beside the missing first product cycle stage, CES preferences imply that prices are a constant mark-up over marginal costs, which pins down real wages. Hence, real wages do not change when exogenous non-productivity shocks occur, such as changes in population or wealth transfers. With non-homothetic preferences prices and markups depend on the willingness to pay, so wages and prices can move differently.

A change in Southern productivity and country size as discussed above has opposite implications for the evolution of terms of trade in both models. On the one hand, the higher imitation rate raises the Northern risk premium which puts pressure on Northern profits. On the other hand, the share of goods manufactured in South (North) increases (decreases). Hence, instantaneous profits of surviving Northern firms rise due to higher Southern demand for remaining Northern products. The latter effect outweighs the former and hence, the innovation rate rises. While in both models relative wage rates move in favor of South, the terms of trade moves in opposite directions. In GH the Northern terms of trade are connected to the change in relative wage rates (prices are a constant markup over marginal costs), and hence deteriorate. In this paper, the terms of trade depend on the willingness to pay of households. Terms of 
trade move in favor of the North as higher Southern relative wages lead to a higher willingness to pay of Southern households for Northern products.

To sum up, non-homothetic preferences account for different adoption times as a function of per capita income and hence complete the product cycle description. In particular, they generate a new first stage that is consistent with stylized facts discussed in Section 4 below. Furthermore, real wages react to changes in parameters with non-homothetic preferences, which alters the prediction on terms-of-trade effects.

\section{Case study: The countertop microwave oven}

The case study illustrates those features of the product cycle emphasized by the theory presented above. It focuses on the product cycle of the countertop microwave oven, a typical household appliance of the 20th century. Our case study shows that the launch of the microwave oven across 16 European markets varies systematically with per capita income, which we use as a proxy for demand. In addition, we show that the pattern of introduction across countries is similar for other major consumer durables like the dishwasher, dryer, freezer, VCR, and washing machine. ${ }^{14}$ The pattern found in the data is difficult to explain by theories stressing the supply side, without assuming a fix cost of exporting that differs across export markets (i.e. beachhead cost). Trade data shows that the United States, where the microwave was first introduced in 1967, started out as a net exporter of microwaves but became a net importer in the mid-1990s. Together with the increase in production in the UK, South Korea, Brazil and Russia in the 1980s and 1990s, it suggests that production of microwaves gradually shifted from North to South.

\subsection{Demand lags}

In 1946, Percy Spencer, an American engineer, while working on radar technology for the U.S. defense company Raytheon Corporation accidentally discovered that microwaves are capable of heating food almost instantly. The story goes that a candy bar in Spencer's pocket melted during an experiment. Spencer realized the commercial potential of his discovery, especially for a high-income market like the US, and Raytheon Corp. filed for patents. In 1947, Raytheon produced the first commercial microwave oven named "Radarange", which was sold to businesses like restaurants. Twenty years later, in 1967, Amana, a division of Raytheon, introduced the first domestic countertop microwave oven, marking the beginning of the use of the microwave in American kitchens (see e.g. Osepchuk 1984).

In the second half of the 20th century, the microwave oven became a beloved household item in kitchens all over the world. We show evidence, which suggests that the pattern of introduction across 16 European countries depends on the level of demand as measured by per capita income. The data was kindly provided by Tellis, Stremersch and Yin (2003). Table 2 in Appendix A.6 shows the year of introduction defined by Tellis, Stremersch and Yin (2003) as

\footnotetext{
${ }^{14}$ The list of countries and products can be found in Table 2 in Appendix A.6.
} 
the first year commercial sales for the microwave oven were registered and GDP per capita in the year the microwave was introduced in the United States. ${ }^{15}$ In 1967, the year the countertop microwave oven was first introduced in the US, GDP per capita was USD 19,522 in the US, whereas it was only USD 9,742 and USD 5,937 in Greece and Portugal, respectively, where the microwave was last introduced in our sample of countries. Spearman's rank correlation coefficient, shown at the bottom of Table 2 , suggests that on average the microwave oven was first introduced in markets with a high GDP per capita, and last introduced in markets with a low GDP per capita. The pattern of introduction is similar for the other consumer durables. Table 1 below shows for each consumer durable the result from regressing the introduction lag $\Delta$ on (relative) GDP per capita and population size in country $i$, where all variables are in logs and relative to the US (see Appendix A.6 for details). Table 1 further suggests that there is a negative relationship between the introduction lag of the microwave and (relative) GDP per capita, controlling for (relative) population sizes. Indeed, we find again a similar relationship for all other consumer durables, as well as for the average across all six consumer durables (i.e. $\Delta$ mean in the first column of Table 1).

Table 1: Correlation between $(\log )$ relative GDP per capita and $(\log )$ introduction lag $\Delta$

\begin{tabular}{|c|c|c|c|c|c|c|c|}
\hline & $\log (\Delta$ mean $)$ & $\log (\Delta d i s h)$ & $\log (\Delta d r y e r)$ & $\log (\Delta$ freeze $)$ & $\log (\Delta$ micro $)$ & $\log (\Delta v c r)$ & $\log (\Delta$ wash $)$ \\
\hline $\log ($ rel GDPpc $)$ & $\begin{array}{l}-0.428 \\
(-3.95)\end{array}$ & $\begin{array}{l}-0.399 \\
(-9.75)\end{array}$ & $\begin{array}{l}-0.427 \\
(-3.61)\end{array}$ & $\begin{array}{l}-0.702 \\
(-2.49)\end{array}$ & $\begin{array}{l}-0.848 \\
(-2.88)\end{array}$ & $\begin{array}{l}-0.124 \\
(-0.88)\end{array}$ & $\begin{array}{l}-0.249 \\
(-1.45)\end{array}$ \\
\hline $\log ($ rel pop $)$ & $\begin{array}{l}-0.109 \\
(-2.41)\end{array}$ & $\begin{array}{l}-0.107 \\
(-6.03)\end{array}$ & $\begin{array}{l}-0.098 \\
(-1.77)\end{array}$ & $\begin{array}{c}0.094 \\
(0.75)\end{array}$ & $\begin{array}{l}-0.221 \\
(-2.48)\end{array}$ & $\begin{array}{l}-0.108 \\
(-3.86)\end{array}$ & $\begin{array}{l}-0.235 \\
(-3.09)\end{array}$ \\
\hline adj. $R^{2}$ & 0.546 & 0.911 & 0.460 & 0.262 & 0.460 & 0.547 & 0.399 \\
\hline \#obs & 16 & 14 & 16 & 15 & 16 & 12 & 15 \\
\hline
\end{tabular}

Notes: t-values in parentheses

\subsection{Export and production patterns}

A look at trade and production data suggests that production of the microwave oven gradually moved from the US abroad.

The left-hand panel in Figure 5 below looks at U.S. import and export data for the same 16 European countries discussed above at the 5 digit SITC level from 1978-2006, which are provided by the Center for International Data at UC Davis (Feenstra 1996, 1997). We observe that the US starts out as a net exporter of microwave ovens at the beginning of the sample period in 1978 and ends up as a net importer at the end of 2006, switching in the mid-1990s. A possible interpretation for the decline in the ratio of exports to exports plus imports is that firms in the 16 European countries mastered the technology to produce microwave ovens, and due to lower production costs were able to compete with US firms in their home markets as well as in the US market. In other words, US firms became less competitive in their export

\footnotetext{
${ }^{15}$ GDP data (PPP, 2005 USD) are taken from Penn World Tables (PWT) 7.0, see Heston, Summers and Aten (2012).
} 
markets and/or European firms became more competitive in the US market, such that US exports relative to U.S. imports decreased. ${ }^{16}$ The export performance of the other products as well as on average across all products (see Appendix 15) is similar, with the exception of the domestic deep freezer.

The right-hand side panel in Figure 5 shows data on the production of the microwave oven of various countries relative to the United States for the time period of 1982-2008, obtained from the Industrial Commodity Production Statistics Database (United Nations Statistics Division 2012). ${ }^{17}$ We observe that the US production of the microwave is declining from the 1980s until 2008, first relative to the UK and South Korea, and later on relative to emerging countries like Brazil and Russia. Again, a possible explanation consistent with the product cycle theory is that the production of microwave oven moves from developed countries to developing countries as firms in these countries acquire the technology to produce microwave ovens and have lower production costs. The production pattern for the washing machine is very similar (see Appendix A.6). Data limitations prevent us from looking into the production patterns for other countries and for the rest of the consumer durables discussed above.
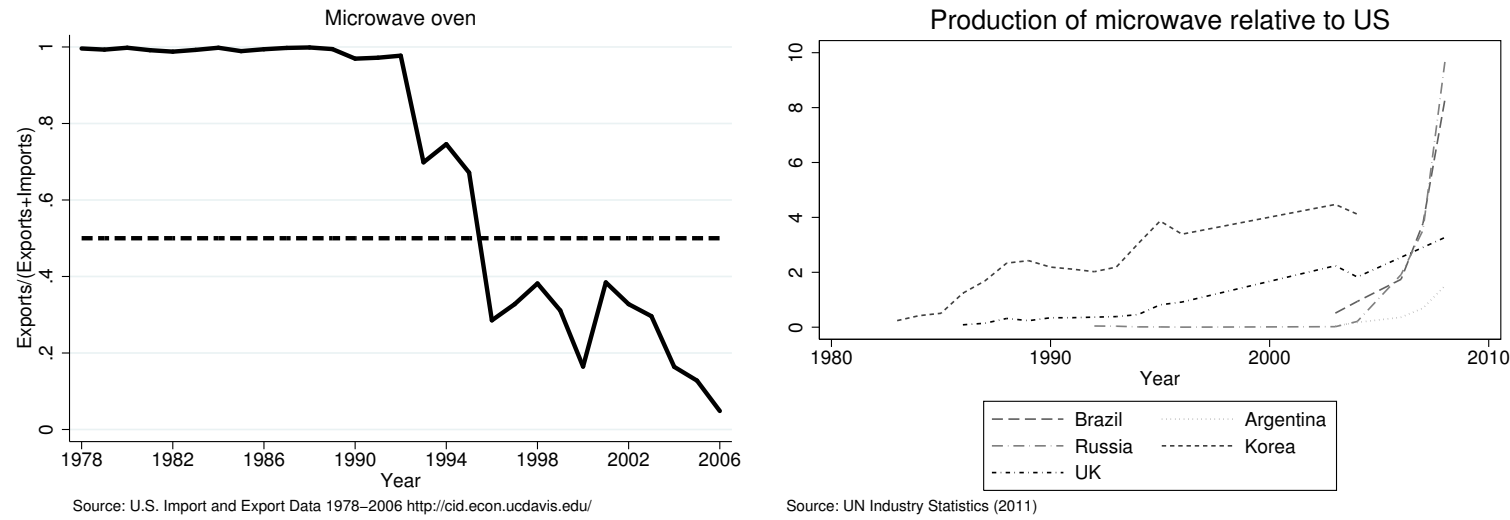

Figure 5: US export ratio for microwave ovens across 16 European countries (left-hand side), and production of microwave oven relative to US (right-hand side)

\section{Extensions}

Due to our assumption of symmetric preferences and identical cost structures the product cycle of product $j$ (i.e. at the firm level) is indeterminate. In order to show that the product cycle we impose in our baseline model emerges from more complex models, without changing the

\footnotetext{
${ }^{16}$ Note that during the first half of the 1980s until the Plaza Accord was signed in 1985, the USD strongly appreciated against all major currencies. This might have (temporarily) added to the decline in US net export of microwaves. The US export performance continues to deteriorate after 1985, although to a somewhat lesser extend.

${ }^{17}$ The data is collected through annual questionnaires sent to national statistical authorities. The data reported by the United Nations Commodity Statistics Yearbook reflect volume (and value) of production sold during the survey period, which is defined as the production carried out at some time, which has been sold (invoiced) during the reference period.
} 
basic channels through which the income distribution operates, we discuss two extensions. It is straightforward to either change the assumptions about preferences or about technology such that the indeterminacy vanishes.

\subsection{Hierarchic preferences}

Following Foellmi and Zweimüller (2006), we assume that households have the following non-homothetic preferences

$$
u(c(j, t))=\int_{j=0}^{N(t)} j^{-\gamma} c(j, t) d j
$$

where the parameter $\gamma \in(0,1)$ determines the "steepness" of the hierarchy, i.e. how fast marginal utility falls in the index $j$. One can view low-indexed products as satisfying more basic needs relative to higher-indexed products. It is straightforward to derive the willingness to pay for good $j$, which is given by $z(j, t) \equiv j^{-\gamma}[u(\cdot) \lambda(t)]^{-1}$, and decreases in the index $j$. In other words, households demand, and therefore Northern firms develop, products along the hierarchy, starting with low-indexed products and gradually moving up the hierarchy ladder. This implies that profit-maximizing prices for Northern products, and hence profits decrease in the index $j$, given all firms have the same cost structure.

We continue to assume that Southern households can afford to consume some products manufactured in North. Which Northern firms do not export and which firms do? First, suppose that no firm in North exports. In that case Southern households would not exhaust their budget constraints and their willingness to pay would become infinitely large. This implies that prices for the lowest-indexed products, which have not yet been imitated by South, become infinitely high. Hence, the firms producing the lowest-indexed products have an incentive to start exporting their products. Second, consider the case where all Northern firms export. In that case, Northern households would not exhaust their budget constraints, and their willingness to pay for an additional product would become infinitely high. This implies that new firms enter the market along the consumption hierarchy, manufacturing products that Southern households cannot afford, and that are therefore not exported.

We keep our assumptions about technology in North. However, instead of assuming that Southern firms target Northern products at random for imitation, we assume that patents expire at time $\widetilde{t}<\infty$, where $\widetilde{t}$ is now deterministic. Random imitation would imply that there might be "holes" in the hierarchy of products. Southern firms must still invest a fixed amount of resources, e.g. build local production facilities, reverse engineer or learn the production process, in order to manufacture products, whose patents have expired, at constant marginal costs. The fixed cost implies that it is never a dominant strategy for a Southern firm to copy a product, which has already been imitated by another Southern firm. After the patent expires the Southern firm imitating the product enters into price competition with the original Northern innovator, which leads to a limit price equal to marginal costs of the Northern firm, and the exit of the Northern firm. 
In sum, this model would generate the following deterministic product cycle in a steady state. At some time $t \geq 0$, the Northern firm $j$ introduces the lowest-indexed product that has not yet been invented. It starts selling its product to Northern households at the price $z_{N}(j, t)$ since only they can afford to purchase new products that satisfy relatively non-essential needs. The price $z_{N}(j, t)$ increases at rate $\gamma g$ until after $\Delta$ periods, which is still determined by $N(t)=N_{S}(t) \exp (g \Delta)$, the Northern firm finds it attractive to lower the price to $z_{S}(j, t)$ and starts exporting its product. ${ }^{18}$ The price $z_{S}(j, t)$ increases at rate $\gamma g$ until after $\widetilde{t}>t+\Delta$ periods the patent expires, a Southern firm copies the product and price competition drives the Northern firm out of the market. The price drops to the marginal cost of production of Northern firms, and stays constant from then on. Hence, such a model would eliminate the indeterminacy of the product cycle. However, the analysis would be substantially more complicated without adding much additional insight.

\subsection{Learning-by-doing}

In the following, we keep our assumptions from the basic model about preferences (Section 2.2) and technology in South (Section 2.3.2). However, we follow Matsuyama (2002) and assume that there is passive learning-by-doing (i.e. externality of the manufacturing process) in the production sector of North. In particular, we assume that producing one unit of output requires $b^{N}(j, t)=b^{N}(Q(j, t)) / N(t)$ units of labor, where $b^{N}(\cdot)$ is a decreasing function of the discounted cumulative output determined by

$$
Q(j, t)=\delta \int_{-\infty}^{t} C(j, s) \exp (\delta(s-t)) d s
$$

where $\delta>0$ can be interpreted as both the speed of learning as well as the rate of depreciation of the learning experience. Again, $C(j, t) \in\{0,(1-\beta) L, L\}$ denotes market demand. Due to depreciation the cumulative learning experience $Q(j, t)$ is bounded from above by $C(j, t)$, and can therefore not exceed $L$. We continue to assume that the creation of a new product requires $F^{N}(t)$ units of labor. As in the previous section, we assume that patents expire after $\widetilde{t}<\infty$ periods.

Again, consider a situation where Southern households can afford to purchase some of the products made in North. Prices of Northern and Southern products are still determined as before. Our assumptions about technology imply that profits of Northern firms increase with production experience, ceteris paribus. In other words, firms which have been in the market for a longer time earn higher profits since their marginal costs are lower. In equilibrium, at any point in time some firms export and some

\footnotetext{
${ }^{18}$ This follows from taking the time derivate of the willingness to pay for the most recently innovated product $N(t)$, which is given in the steady state by $\dot{z}_{N}(N(t), t) / z_{N}(N(t), t)=r-\rho-g$. In a steady state where the allocation of resources in North is constant across sectors the price of the newest product must be constant, i.e. $r=\rho+g$. In the steady state $n=N_{S}(t) / N(t)$ must be constant too, so that the price of any product $j$ evolves over time as follows $\dot{z}_{i}(j, t) / z_{i}(j, t)=r-\rho-(1-\gamma) g$ for $i \in\{N, S\}$. Hence, using $r=\rho+g$ yields $\dot{z}_{i}(j, t) / z_{i}(j, t)=\gamma g$. Note that the firm selling the newest product must be indifferent in equilibrium whether to export or not, i.e. $\left[z_{N}\left(N_{S}(t), t\right)-1\right](1-\beta)=\left[z_{S}\left(N_{S}(t), t\right)-1\right]$, where $z_{N}\left(N_{S}(t), t\right)=n^{-\gamma} z_{N}(N(t), t)$.
} 
sell exclusively to Northern households. Hence, there must be some threshold value $Q\left(N_{S}(t), t\right)$, implicitly defined by $\left[z_{N}\left(N_{S}(t), t\right)-w^{N}(t) b^{N}\left(Q\left(N_{S}(t), t\right)\right) / N(t)\right](1-\beta)=$ $\left[z_{S}\left(N_{S}(t), t\right)-w^{N} b^{N}\left(Q\left(N_{S}(t), t\right)\right) / N(t)\right]$, at which a Northern firm is indifferent between exporting or not. Below this threshold value the profits from excluding Southern households exceed the profits from exporting, and vice versa. In other words, below the threshold value $Q\left(N_{S}(t), t\right)$ the price effect dominates the market size effect, and vice versa.

Hence, this model would imply that products go through the following cycle in steady state. A new product introduced by a Northern firm is first sold at high prices $z_{N}$ only in the domestic market since this firm has a relatively low productivity level at which the price effect dominates the market size effect. The Northern firm finds it optimal to lower the price to $z_{S}$ and start exporting its product after $\Delta$ periods (still determined as before) since incomes in South grow and the Northern firm becomes more productive. At time $\tilde{t}>t+\Delta$ the patent of the product expires, and it is imitated by a Southern firm. Price competition implies that the limit price drops to marginal costs of Northern firms, and the Northern firm exits the market. From then onwards the product is imported by North from South.

\section{Conclusion}

Vernon's (1966) celebrated product cycle theory hypothesizes that new products go through the following stages. In the first stage, new products are developed and introduced in high-income countries. Later in the cycle, incomes in the poorer countries have grown sufficiently such that demand for these products appears there. Thus, products that were only consumed in high-income countries before are now exported. In the third stage, production moves from high-income countries to low-income countries because they have learned the technology to produce these goods and are able to produce them at lower costs.

The paper contributes to the literature in building a dynamic general-equilibrium model that is able to generate the three stages of the product cycle described by Vernon (1966). In our model, a wealthy North develops new products, which a poor South randomly attempts to copy. The incentives to innovate and imitate are determined by the distribution of income across regions such that the demand side is an important determinant of the different stages of the product cycle. Aside from analyzing changes in Southern labor productivity and a larger Southern population, we elaborate the effects of a redistribution of wealth between North and South such that inequality across regions decreases. We show that a decrease in inequality across regions leads to a decline in the innovation rate and hence a slowdown of imitation activity in South, for a given share of South in total production. Since Southern households are wealthier after the redistribution of income, they can afford to purchase a higher share of goods available in the world market - in particular more newer goods produced in North. Thus, firms in the North will export their products sooner. In other words, the first stage of the cycle becomes shorter. At the same time the average duration new products are manufactured in North increases because imitation activity in South has slowed down. Firms in South master the technology to copy a good later, so that on average it takes longer for the production to 
move to South because of the cost advantage. Hence, the second stage of the product cycle where new goods are exported by North to South gets longer. Therefore, the third stage of the cycle where the products are imitated and exported to North becomes shorter.

Supply based approaches cannot capture the fact that adoption time and per capita incomes are correlated, i.e. that poorer countries start consuming products later in the cycle. Incorporating non-homothetic preferences into these types of models enables us to formalize the product cycle hypothesis and analyze the effects of the demand side on the product cycle. Our model is consistent with the stylized fact that the product adoption strongly correlates with per capita income. We show that the microwave oven (and other common consumer durables) appear to have gone (or still go) through a "typical" product cycle. In particular, new products are not introduced simultaneously across countries and the lag in introduction depends negatively on relative GDP per capita, i.e. relative to the first country where a product is introduced. In other words, new products are introduced in affluent countries before they are introduced in less prosperous countries.

The relevance of the product cycle theory is essentially an empirical question. Our analysis delivers empirically testable predictions on the long-term movements in the terms of trade to exogenous changes in (relative) labor productivity, population size, and per capita income. At the same time, empirical tests help to put the product cycle theory into perspective. On the theoretical side as production processes are ever more segmented across countries, it might be interesting to explore the consequences for the product cycle of allowing $R \& D$ to take place in a different region than production (e.g. a product like the iPad, which is designed in the United States and assembled in China). We consider all these topics interesting directions for future research.

\section{References}

Acemoglu, Daron, Gino A. Gancia, and Fabrizio Zilibotti. 2012. "Competing Engines of Growth: Innovation and Standardization." Journal of Economic Theory, 147(2): 570-601.

Falkinger, Josef. 1990. "Innovator-Imitator Trade and the Welfare Effects of Growth." Journal of the Japanese and International Economies, 4(2): 157-172.

Feenstra, Robert C. 1996. "U.S. Imports, 1972-1994: Data and Concordances." NBER Working Paper 5515.

Feenstra, Robert C. 1997. "U.S. Exports, 1972-1994, with State Exports and other U.S. Data." NBER Working Paper 5990.

Flam, Harry, and Elhanan Helpman. 1987. "Vertical Product Differentiation and North-South Trade." The American Economic Review, 77(5): 810-822.

Foellmi, Reto, and Josef Zweimüller. 2006. "Income Distribution and Demand-Induced Innovations." The Review of Economic Studies, 73: 941-960.

Grossman, Gene, and Elhanan Helpman. 1991. "Endogenous Product Cycles." The Economic Journal, 101(408): 1214-1229. 
Heston, Alan, Robert Summers, and Bettina Aten. 2012. "Penn World Table Version 7.1." Center for International Comparisons for International Comparisons of Production, Income and Prices at the University of Pennsylvania.

Jorgenson, Dale, and Khuong Vu. 2011. "Technology And Labor Productivity." Development Outreach, 13(1): 45-45.

Krugman, Paul. 1979. "A Model of Innovation, Technology Transfer, and the World Distribution of Income." The Journal of Political Economy, 87(2): 253-266.

Kugler, Maurice, and Josef Zweimüller. 2005. "National Income Distributions and International Trade Flows." Working Paper.

Lane, Philip R., and Gian Maria Milesi-Ferretti. 2007a. "Should Europe care about global imbalances?" VoxEU.org.

Lane, Philip R., and Gian Maria Milesi-Ferretti. 2007b. "The external wealth of nations mark II: Revised and extended estimates of foreign assets and liabilities, 1970-2004." Journal of International Economics, 73: 223-250.

Matsuyama, Kiminori. 2000. "A Ricardian Model with a Continuum of Goods under Nonhomothetic Preferences: Demand Complementarities, Income Distribution, and North-South Trade." The Journal of Political Economy, 108(6): 1093-1120.

Matsuyama, Kiminori. 2002. "The Rise of Mass Consumption Societies." The Journal of Political Economy, 110(5): 1035-1070.

McMillan, Margaret, and Dani Rodrik. 2011. "Globalization, Structural Change, and Productivity Growth." Working Paper.

Osepchuk, John M. 1984. "A History of Microwave Heating Applications." IEEE Transactions on Microwave Theory and Techniques, 32(9): 1200-1224.

Posner, M.V. 1961. "International Trade and Technical Change." Oxford Economic Papers, New Series, 13(3): 323-341.

Stokey, Nancy L. 1991. "The Volume and Composition of Trade Between Rich and Poor Countries." The Review of Economic Studies, 58(1): 63-80.

Tellis, Gerard J., Stefan Stremersch, and Eden Yin. 2003. "The International Takeoff of New Products: The Role of Economics, Culture, and Country Innovativeness." Marketing Science, 22(2): 188-208.

United Nations Statistics Division. 2012. "Industrial Commodity Production Statistics Database." http://unstats. un. org/unsd/industry/ics_intro. asp.

Vernon, Raymond. 1966. "International Investment and International Trade in the Product Cycle." The Quarterly Journal of Economics, 80(2): 190-207.

Vernon, Raymond. 1979. "The Product Cycle Hypothesis in a New International Environment." Oxford Bulletin of Economics and Statistics, 41(4): 255-267.

World Bank. 2014. "World Development Indicators." 


\section{A Appendix}

\section{A.1 Household problem}

Households maximize logarithmic intertemporal utility, where consumption $c(j, t)$ is its control, and asset holdings $a(t)$ its (endogenous) state variable

$$
\max _{\{c(j, t)\}_{t=0}^{\infty}} U(0)=\int_{0}^{\infty} \exp (-\rho t) \log u\left(\{c(j, t)\}_{j=0}^{N(t)}\right) d t
$$

where $\rho>0$ denotes the time preference rate, subject to the non-negativity constraint $c(j, t) \geq$ 0 , and the flow budget constraint

$$
\dot{a}(t)=r(t) a(t)+w(t)+T(t)-e(t)
$$

with $a(0) \geq 0, c(j, t) \in\{0,1\}$, and $e(t)=\int_{0}^{N(t)} p(j, t) c(j, t) d j$. Furthermore, households face a no-Ponzi game condition of the following form

$$
\lim _{t \rightarrow \infty} \exp \left(-\int_{0}^{t} r(s) d s\right) a(t)=0
$$

where $r(t)$ denotes the risk-free interest rate. Households take the time paths of the interest rate, the wage rate, prices for all goods $j$, as well as the set of differentiated products in the economy $\{r(t), w(t), p(j, t), N(t)\}_{t=0}^{\infty}$ as given. The current value Hamiltonian is given by

$$
H(t, c(j), a, \lambda, \mu)=\log u(\cdot)+\lambda(t)[r(t) a(t)+w(t)+T(t)-e(t)]+\sum_{j}^{\infty} \xi(j, t) c(j, t)
$$

where $\lambda(t)$ denotes the costate variable on the flow budget constraint and $\xi(j, t)$ the one on the non-negativity constraints. The maximum principle conditions are

$$
\begin{gathered}
\max _{\{c(j, t)\}_{j=0}^{N(t)}} H(t, c(j), a, \lambda, \mu) \quad \text { for all } t \in[0, \infty], j \in[0, N(t)]: \\
u(\cdot)^{-1}-\lambda(t) p(j, t)=0, \quad c(j, t)=1 \\
u(\cdot)^{-1}-\lambda(t) p(j, t) \leq 0, \quad c(j, t)=0 \\
\lambda(t) r(t)=-\dot{\lambda}(t)+\rho \lambda(t) \\
\dot{a}(t)=r(t) a(t)+w(t)+T(t)-e(t) \\
\lim _{t \rightarrow \infty} \exp (-\rho t) \lambda(t) a(t)=0
\end{gathered}
$$




\section{A.2 Derivation of transitional dynamics}

Using the resource constraint of South, the relationship between $g$ and $g^{S}$, the resource constraint of North to substitute for $g$, and the balance of payments to substitute for $n$ (assuming that it is balanced period by period), we obtain the $\dot{m}$ - schedule

$$
\frac{\dot{m}}{m}=\left(\frac{1}{F^{N} /\left(b^{N} L\right)}\right)\left\{\frac{\lambda \beta z_{N}}{\beta+(1-\beta) z_{N}}-\left[(1-\beta)\left(\frac{1}{b^{N}}-1\right)+m-F\left(\frac{\beta / b^{S}}{m}-1\right)\right]\right\}
$$

where $\lambda=\lambda_{N} / \lambda_{S}$ which is constant and equal to its steady state value, and $F=\frac{F^{N} /\left(b^{N} L\right)}{F^{S} /\left(b^{S} L\right)}$. The $\dot{m}=0$ locus is determined by

$$
\frac{\beta \lambda z_{N}}{\beta+(1-\beta) z_{N}}=(1-\beta)\left(\frac{1}{b^{N}}-1\right)+m-F\left(\frac{\beta / b^{S}}{m}-1\right) .
$$

It is straightforward to show that $d z_{N} / d m>0, z_{N}(m) \rightarrow-\infty$ as $m \rightarrow 0$, and $z_{N}(m)$ equals a positive constant larger than one as $m \rightarrow \beta / b^{S}$ if and only if $(1-\beta)\left(1 / b^{N}-1\right)+\beta / b^{S}>\lambda$ (this simply requires inequality between North and South to be sufficiently high). Thus, the $\dot{m}=0$ locus is increasing in the $\left(z_{N}, m\right)$-space. For values of $z_{N}$ above the $\dot{m}=0$ locus, $\dot{m}>0$ and for values of $z_{N}$ below the $\dot{m}=0$ locus, $\dot{m}<0$.

The $\dot{z}_{N}$ - schedule is obtained by using the balance of payments, the Northern and Southern resource constraints, the definition of the hazard rate, the Euler equation, and North's zero-profit condition

$$
\begin{aligned}
\frac{\dot{z}_{N}}{z_{N}} & =\left(\frac{1}{F^{N} /\left(b^{N} L\right)}\right)\left\{\left(z_{N}-1\right)(1-\beta)+\frac{\lambda \beta z_{N}}{\beta+(1-\beta) z_{N}}\right. \\
& \left.-\left[(1-\beta)\left(\frac{1}{b^{N}}-1\right)+m+\frac{\rho F^{N}}{b^{N} L}+F\left(\frac{m}{1-m}\right)\left(\frac{\beta / b^{S}}{m}-1\right)\right]\right\} .
\end{aligned}
$$

The $\dot{z}_{N}=0$ locus is determined by

$$
\begin{aligned}
(1-\beta)\left(z_{N}-1\right)+\frac{\beta \lambda z_{N}}{\beta+(1-\beta) z_{N}} & =(1-\beta)\left(\frac{1}{b^{N}}-1\right) \\
& +m+\frac{\rho F^{N}}{b^{N} L}+F\left(\frac{m}{1-m}\right)\left(\frac{\beta / b^{S}}{m}-1\right) .
\end{aligned}
$$

The slope of the $\dot{z}_{N}=0$ locus is given by

$$
\frac{d z_{N}}{d m}=\frac{\left[\beta+(1-\beta) z_{N}\right]^{2}}{\beta^{2} \lambda+(1-\beta)\left[\beta+(1-\beta) z_{N}\right]^{2}}\left[1-\frac{F}{(1-m)^{2}}\left(1-\beta / b^{S}\right)\right] .
$$

We define $\widetilde{m} \equiv 1-\sqrt{F\left(1-\beta / b^{S}\right)}>0$ with $\beta / b^{S}<1$, and where $\widetilde{m}>0$ requires that $\left(1-\beta / b^{S}\right)^{-1}>F$, which holds e.g. in the case of identical technology, i.e. $F=1$. It follows that $d z_{N} / d m>0$ if $m<\widetilde{m}$, and vice versa. In other words, the $\dot{z}_{N}=0$ locus is decreasing for $m \in\left(\widetilde{m}, \beta / b^{S}\right)$, and increasing for $m \in(0, \widetilde{m})$ in the $\left(z_{N}, m\right)$-space. We note that $z_{N}(m) \rightarrow-\infty$ as $m \rightarrow 1$ and $z_{N}(m)$ converges to a constant as $m \rightarrow 0$. We conclude, 
for values of $z_{N}$ above the $\dot{z}_{N}=0$ locus, $\dot{z}_{N}>0$ and for values of $z_{N}$ below the $\dot{z}_{N}=0$ locus, $\dot{z}_{N}<0$.

Hence, we have a system of two differential equations in $m$ (state variable) and $z_{N}$ (choice variable), whose solution is saddle-path stable. Figure 6 below shows the phase diagram. We see that if $m$ is below (above) its steady state value $m^{*}$ it converges monotonically towards the steady state along the saddle-path.

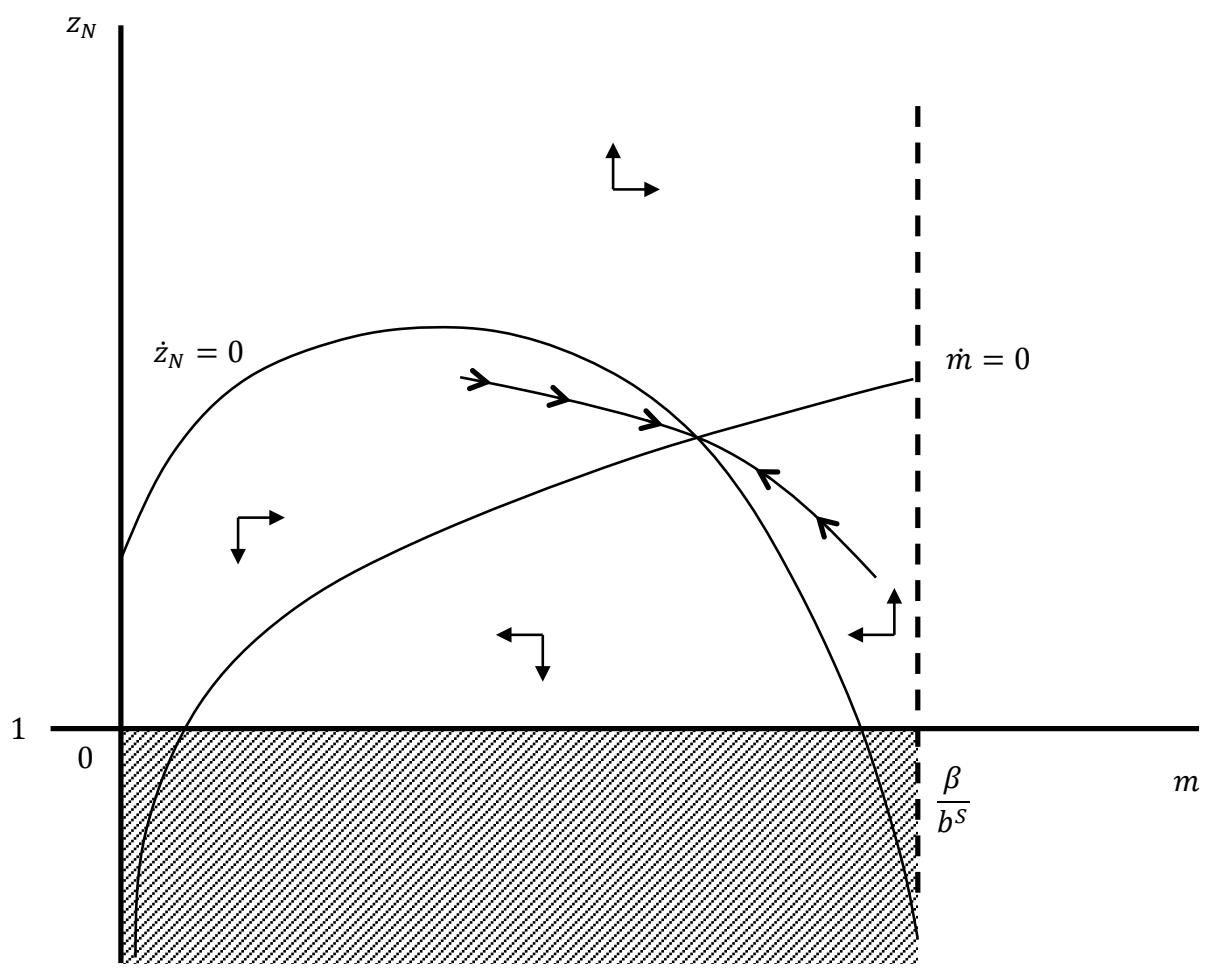

Figure 6: Phase diagram

\section{A.3 Budget constraints}

The intertemporal budget constraint of households in North is in the steady state given by

$$
N(t)\left\{m+(n-m)\left[\beta+(1-\beta) z_{N}\right]+(1-n) z_{N}\right\}=(r-g) a_{N}(t)+w^{N}(t)-T_{N}(t)
$$

where $y_{N}(t)=a_{N}(t)+w^{N}(t) /(r-g)-T_{N}(t) /(r-g)$ denotes the lifetime income of a Northern household. We observe that Northern households save only out of their capital income (note that $r-g=\rho$ ), and consume all their labor income (and possible transfer income). In other words, the marginal propensity to consume out of labor and transfer income is one. Similarly, in the steady state the intertemporal budget constraint of households in South becomes

$$
N(t)\left\{m+(n-m)\left[\beta+(1-\beta) z_{N}\right]\right\}=(r-g) a_{S}(t)+w^{S}(t)+T_{S}(t)
$$


where $y_{S}(t)=a_{S}(t)+w^{S}(t) /(r-g)+T_{S}(t) /(r-g)$ denotes the lifetime income of a household in South. Similarly to Northern households, Southern households save only out of capital income and consume all labor income. Hence, relative lifetime incomes per capita in the steady state are (endogenously) determined by

$$
\frac{y_{S}(t)}{y_{N}(t)}=\frac{\rho a_{S}(t)+w^{S}(t)+T_{S}(t)}{\rho a_{N}(t)+w^{N}(t)-T_{N}(t)}
$$

\section{A.4 Balance of payments}

The intertemporal budget constraint of households in South, the resource constraint in South, and the zero-profit condition in South imply the balance of payments as stated in the text. Due to Walras' law, the intertemporal budget constraint of North is redundant. We drop the time index $t$ where no confusion arises. The balance of payments in present value form at $t=0$ is given by

$$
\begin{aligned}
0 & =\left\{\int_{0}^{\infty}\left[(1-\beta) L N^{S} \omega^{N} b^{N}-\beta L\left(N_{S}-N^{S}\right) z_{S}\right] \exp \left(-\int_{0}^{t} r(s) d s\right) d t\right\} \\
& +\int_{0}^{\infty} \beta L T_{S} \exp \left(-\int_{0}^{t} r(s) d s\right) d t \\
& +\left\{\beta L a_{S}(0)-\int_{0}^{\infty} N^{S}\left[\pi^{S}-g^{S} v^{S}\right] \exp \left(-\int_{0}^{t} r(s) d s\right) d t\right\}
\end{aligned}
$$

where we used $\beta L N=\dot{N}^{S} F^{S}+N^{S} b^{S} L$ from the resource constraint, $v^{S}=\omega^{S} F^{S}$ from the zero-profit condition, and a no-Ponzi game condition. The first two lines denote the current account, which consists of the trade balance and net transfer payments. The third line denotes net foreign asset holdings. In the steady state, we have that $r$ and $\pi^{S}$ are constant, $N^{S}$ grows at a constant rate $g^{S}=g$, and $v^{S}=\pi^{S} / r$. This implies that net foreign assets become $\left\{\beta L a_{S}(0)-N^{S}(t) \pi^{S} / r\right\}$. Hence, the balance of payments in the steady state is determined by

$0=\left\{N^{S}(t)(1-\beta) L \omega^{N} b^{N}-\left(N_{S}(t)-N^{S}(t)\right) z_{S}(t) \beta L\right\}+\beta L T_{S}(t)+\left\{\beta L a_{S}(t)-N^{S}(t) \pi^{S} / r\right\}$

which holds for all $t$ in steady state, in particular at $t=0$. Hence, it becomes obvious that if we assume initial wealth at time $t=0$ of households in South $\beta L a_{S}(t)$ to be exactly equal to the present discounted value of aggregate firm profits in South $N^{S}(t) v^{S}(t)$, net foreign assets will remain zero in steady state. We see that if Southern households would inherit sufficiently large asset holdings they could run a permanent trade deficit (even in the absence of transfers from North).

\section{A.5 Simulations}

We choose the following parameter configuration for our baseline simulation: $L=1, F^{N}=$ $F^{S}=5, b^{N}=b^{S}=0.75, \beta=0.5, \rho=0.04$, and $T=0$. 


\section{A.5.1 Change in Southern labor productivity}

Figures 7-8 show the comparative statics results of a change in labor productivity in production in the South. Figures 9-10 show the comparative statics results of a change in labor productivity in R\&D in South.
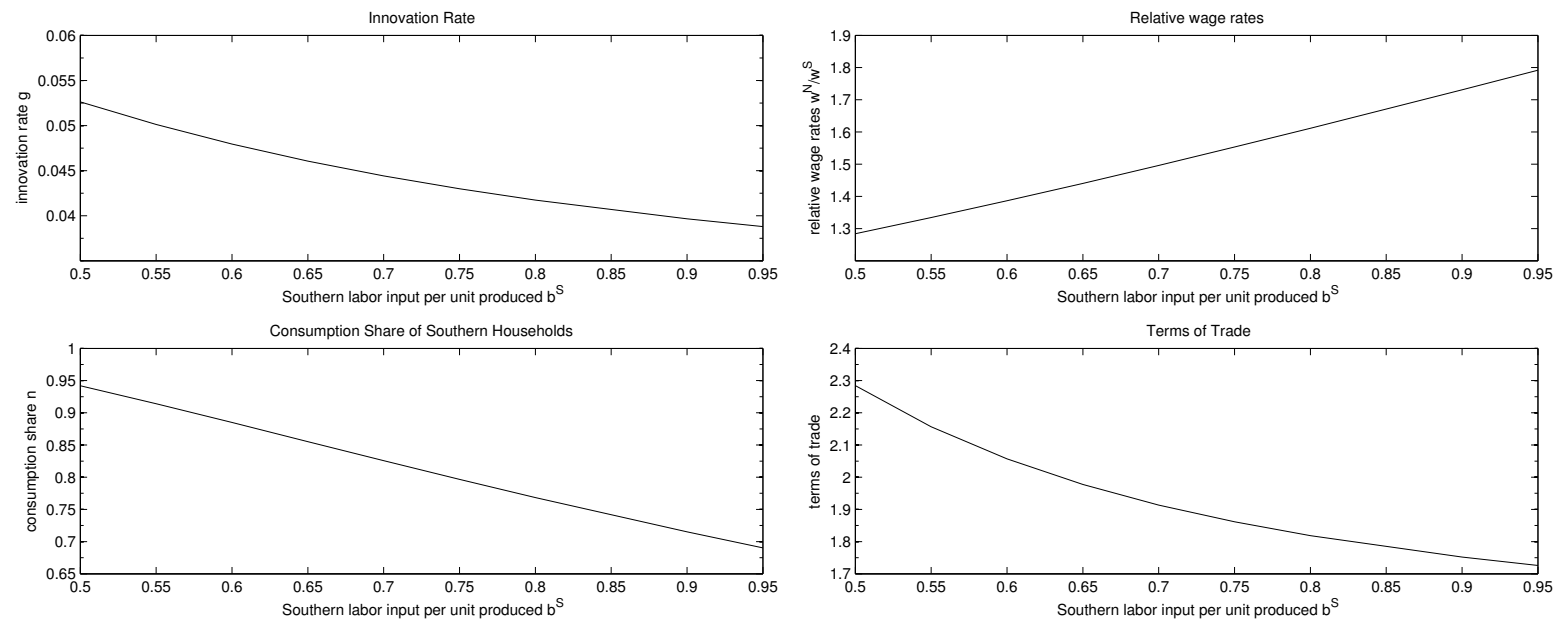

Figure 7: Upper panel: Effect on innovation rate and consumption share of the South. Lower panel: Effect on relative wages

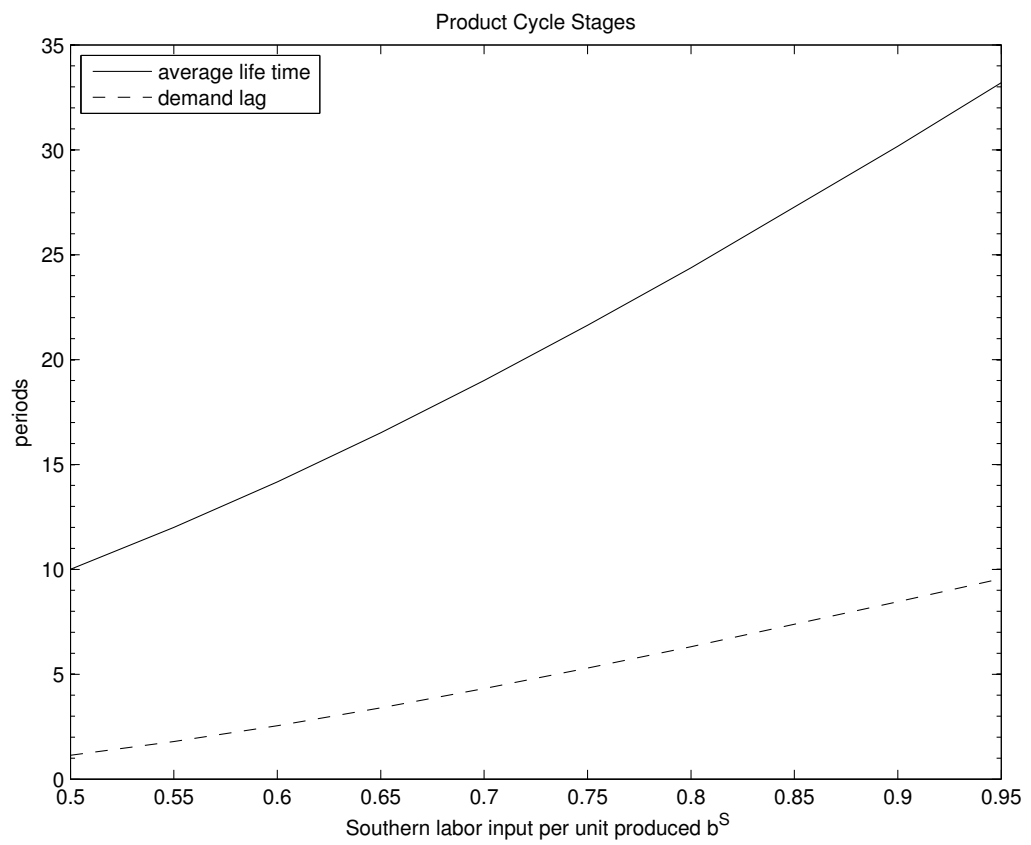

Figure 8: Effect on the stages of the product cycle 

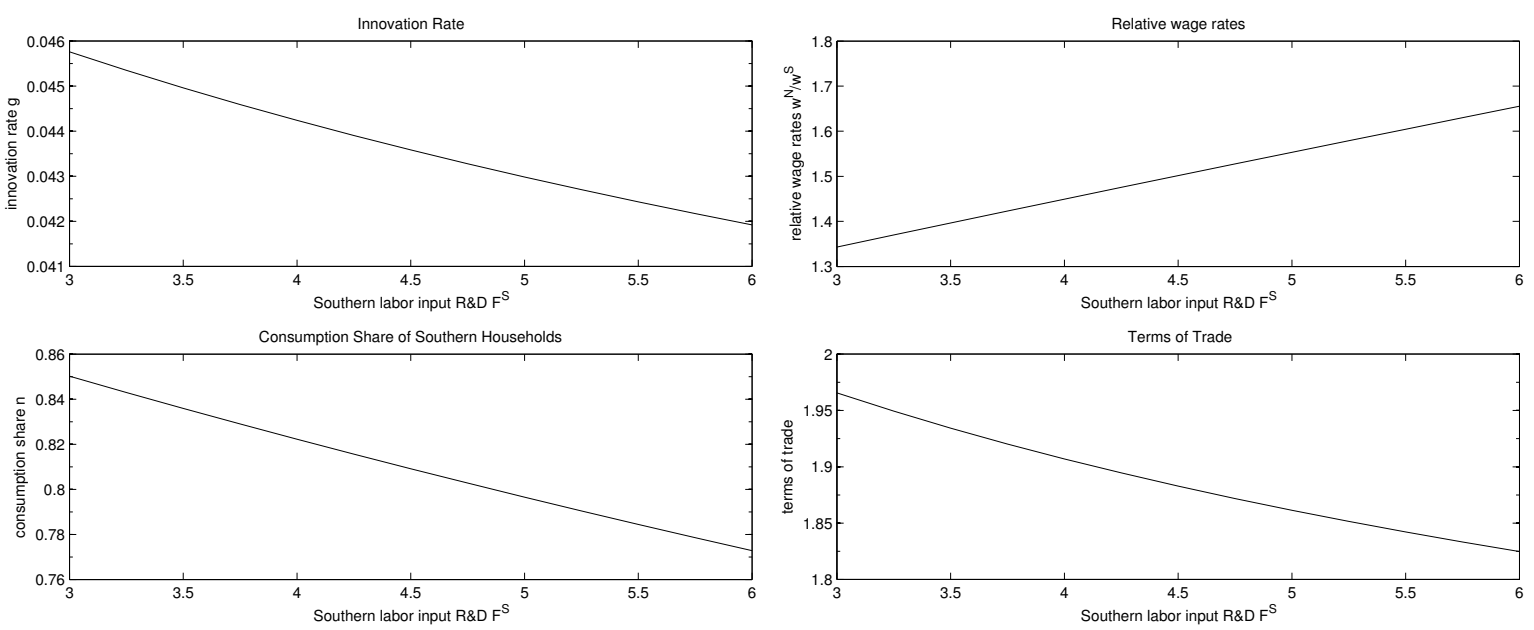

Figure 9: Upper panel: Effect on innovation rate and consumption share of South. Lower panel: Effect on relative wages

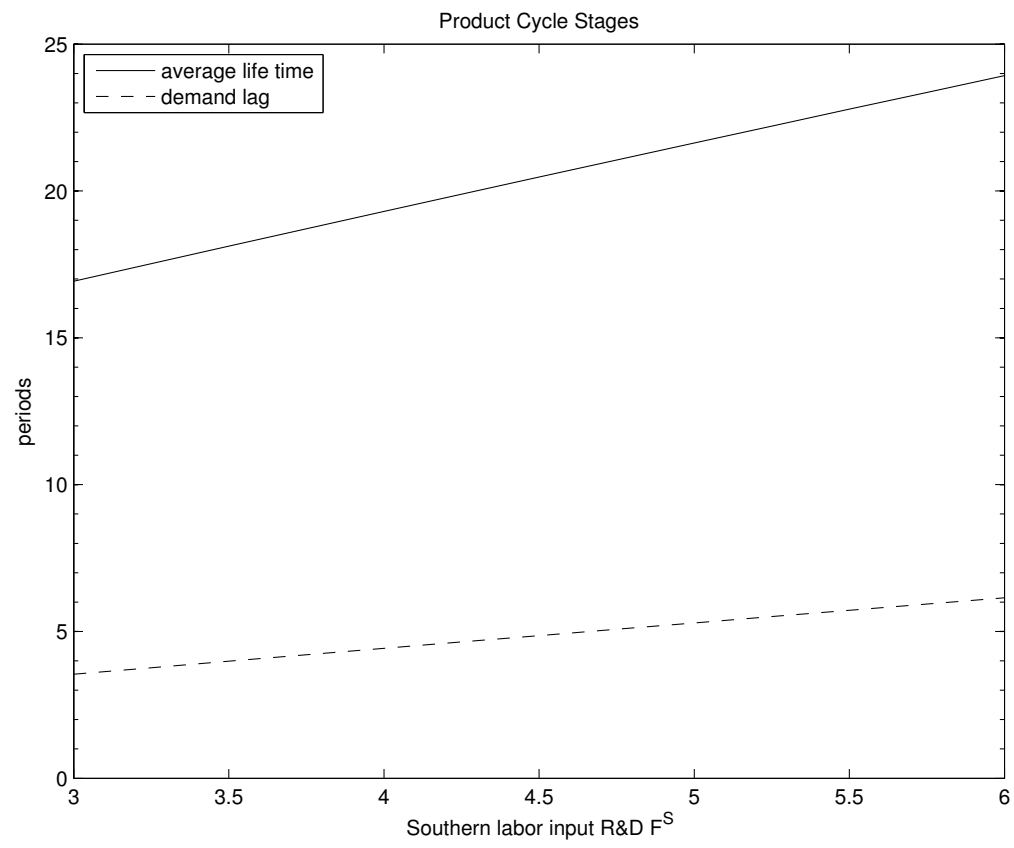

Figure 10: Effect on the stages of the product cycle

\section{A.5.2 Changes in inequality across regions}

Figures 11-12 depict the effects of an increase in inequality across regions due to a regressive transfer, i.e. a transfer from poor South to rich North. 

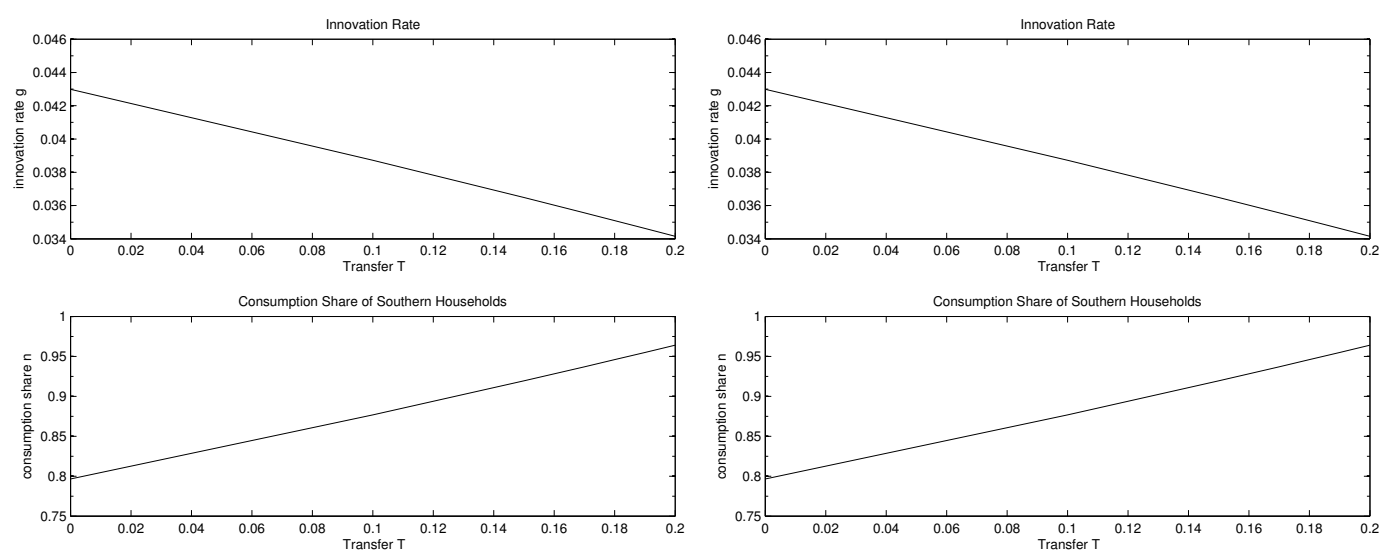

Figure 11: Upper panel: Effect on innovation rate and consumption share of the South. Lower panel: Effect on relative wage rate and terms of trade

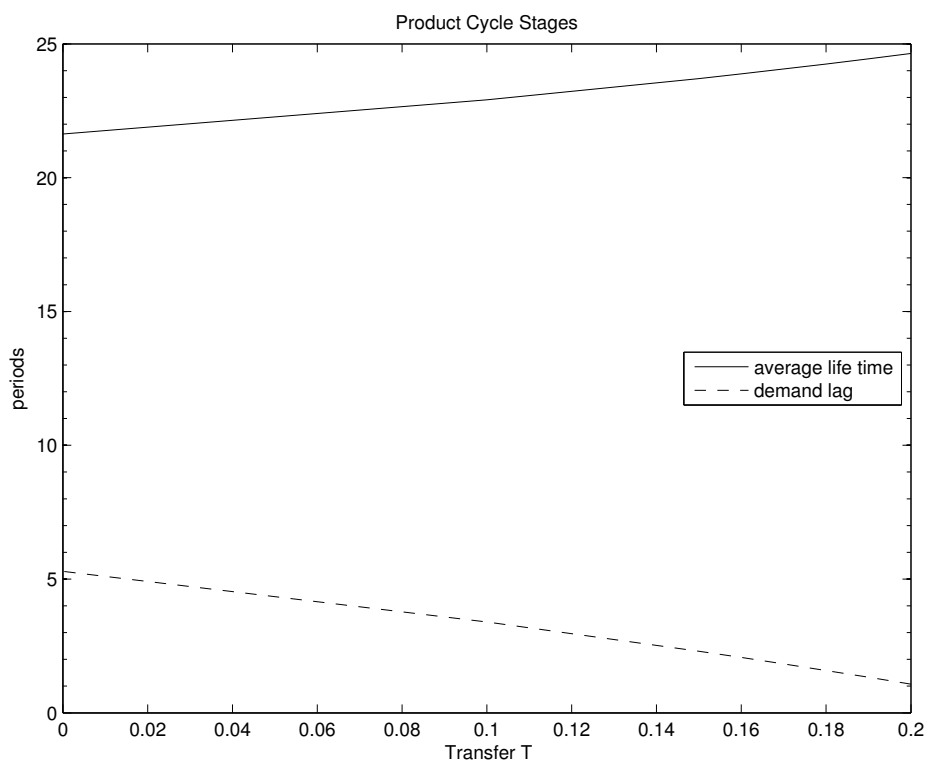

Figure 12: Effect on stages of the product cycle

\section{A.5.3 Changes in Southern population}

Figures 13-14 show the effects of an increase in Southern population. 

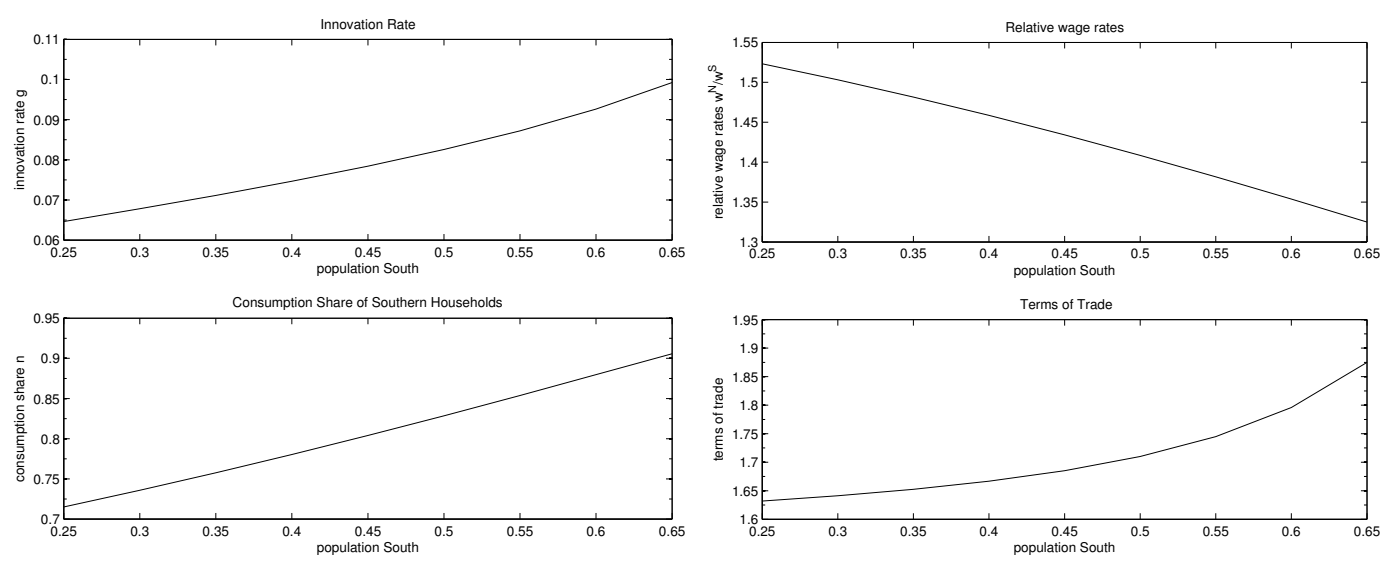

Figure 13: Upper panel: Effect on innovation rate and consumption share of South. Lower panel: Effect on relative wage rate and terms of trade

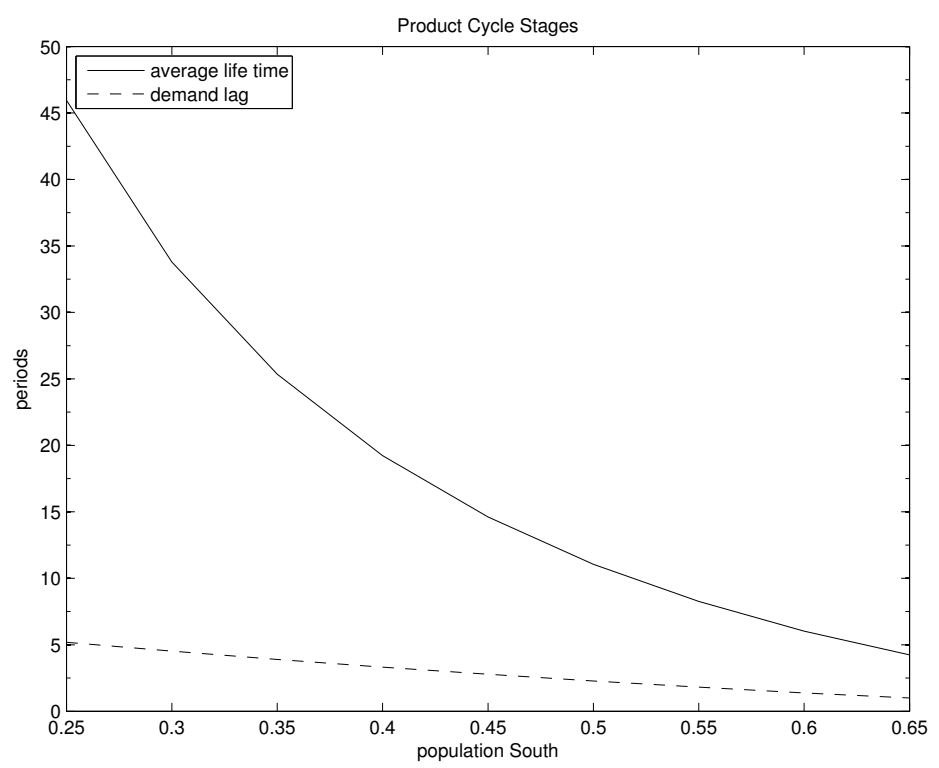

Figure 14: Effect on stages of the product cycle

\section{A.6 Suggestive evidence}

\section{A.6.1 Demand lags}

A web search readily shows that all of the products in Table 2 were first introduced in the United States: the electric dishwasher in 1950 by Hobart Corp., the automatic electric clothes dryer in 1949 by Hamilton Manufacturing Corp. and General Electric, the domestic deep freezer in 1949 by General Electric, the countertop microwave oven in 1967 by Amana Corp., the VCR in 1965 by Sony, Ampex, and RCA, and the automatic electric washing machine in 1947 by Bendix and General Electric.

We estimate the following model with OLS:

$$
\log \left(\Delta_{i j}\right)=\beta_{0}+\beta_{1} \log \left(\frac{G D P p c_{i j}}{G D P p c_{U S}}\right)+\beta_{2} \log \left(\frac{\text { Pop }_{i j}}{\text { Pop }_{U S}}\right)+\varepsilon_{i j}
$$


where $\Delta_{i j}$ denotes the introduction lag, defined as the number of years that elapsed until product $j$ was introduced in country $i, G D P p c_{i j}$ and $P o p_{i j}$ denote GDP per capita and population size in country $i$ at the time product $j$ was introduced in the US, respectively. The coefficient $\beta_{1}$ shows the importance of (relative) GDP per capita, holding relative population sizes constant. We expect $\beta_{1}$ to be negative.

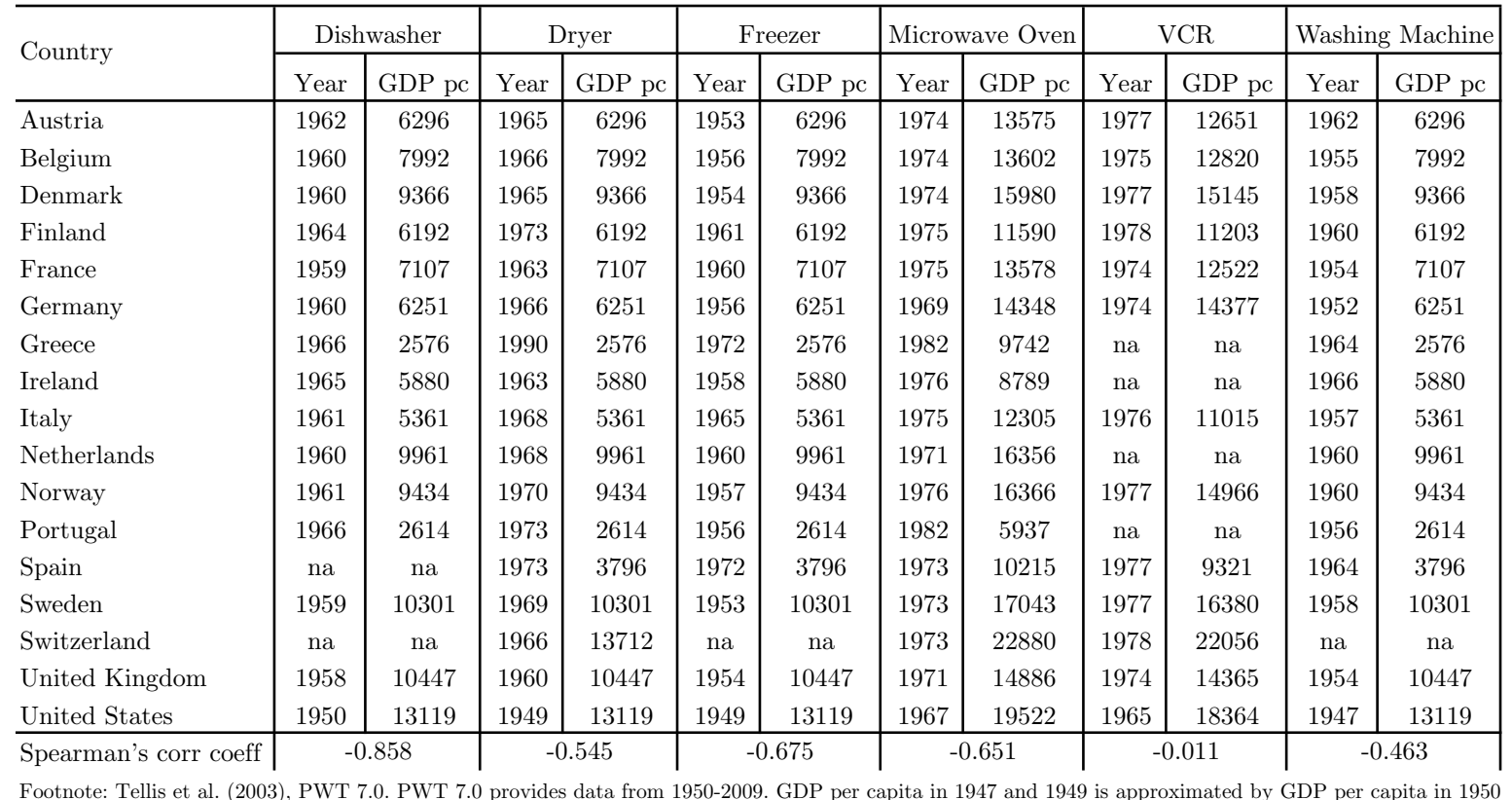

Table 2: Introduction of 6 major consumer durables across European countries and the United States

\section{A.6.2 Export and production patterns}
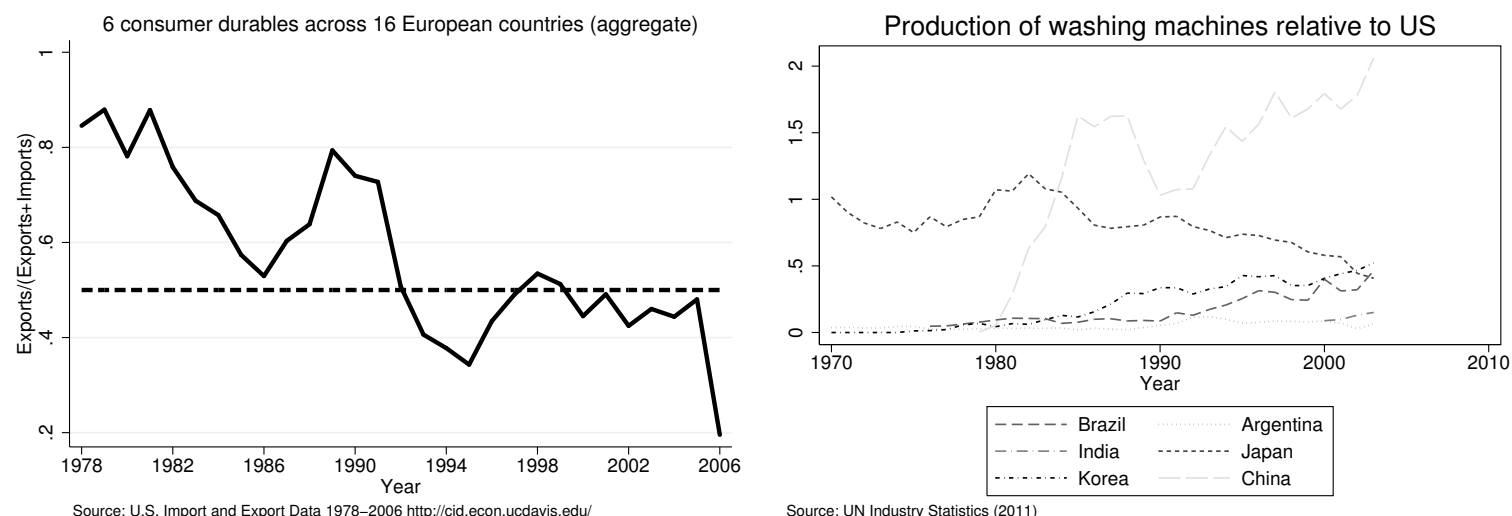

Figure 15: US export performance across all 6 consumer durables and 16 European countries (left-hand side), and production of the washing machine relative to the US (right-hand side) 


\section{Recent SNB Working Papers}

2015-4 Reto Foellmi, Sandra Hanslin and Andreas Kohler: A dynamic North-South model of demand-induced product cycles.

2015-3 Katarina Juselius and Katrin Assenmacher: Real exchange rate persistence: The case of the Swiss franc-US dollar rate.

2015-2 Lucas Marc Fuhrer, Basil Guggenheim and Silvio Schumacher: Re-use of collateral in the repo market.

2015-1 Pinar Yeşin: Capital flow waves to and from Switzerland before and after the financial crisis.

2014-13 Thomas Nitschka: Have investors been looking for exposure to specific countries since the global financial crisis? - Insights from the Swiss franc bond market.

2014-12 Christian Grisse and Thomas Nitschka: Exchange rate returns and external adjustment: evidence from Switzerland.

2014-11 Rina Rosenblatt-Wisch and Rolf Scheufele: Quantification and characteristics of household inflation expectations in Switzerland.

2014-10 Gregor Bäurle and Daniel Kaufmann: Exchange rate and price dynamics in a small open economy - the role of the zero lower bound and monetary policy regimes.

2014-9 Matthias Gubler and Christoph Sax: Skill-Biased Technological Change and the Real Exchange Rate.

2014-8 Tommaso Mancini Griffoli, Christoph Meyer, Jean-Marc Natal and Attilio Zanetti: Determinants of the Swiss Franc Real Exchange Rate.
2014-7 Konrad Adler and Christian Grisse: Real exchange rates and fundamentals: robustness across alternative model specifications.

2014-6 Matthias Gubler: Carry Trade Activities: A Multivariate Threshold Model Analysis.

2014-5 Raphael A. Auer and Aaron Mehrotra: Trade linkages and the globalisation of inflation in Asia and the Pacific.

2014-4 Cyril Monnet and Thomas Nellen: The Collateral Costs of Clearing.

2014-3 Filippo Brutti and Philip Sauré: Repatriation of Debt in the Euro Crisis: Evidence for the Secondary Market Theory.

2014-2 Simone Auer: Monetary Policy Shocks and Foreign Investment Income: Evidence from a large Bayesian VAR.

2014-1 Thomas Nitschka: The Good? The Bad? The Ugly? Which news drive (co)variation in Swiss and US bond and stock excess returns?

2013-11 Linda S. Goldberg and Christian Grisse: Time variation in asset price responses to macro announcements.

2013-10 Robert Oleschak and Thomas Nellen: Does SIC need a heart pacemaker?

2013-9 Gregor Bäurle and Elizabeth Steiner: How do individual sectors respond to macroeconomic shocks? A structural dynamic factor approach applied to Swiss data.

From 2015, this publication series will be renamed SNB Working Papers.

All SNB Working Papers are available for download at: www.snb.ch, Research

Subscriptions or individual issues can be ordered at: Swiss National Bank

Library

P.O. Box

$\mathrm{CH}-8022$ Zurich

Phone: +41446313284

Fax: +41446318114

E-mail: library@snb.ch 
